OPEN ACCESS

Edited by:

Zhenxing Shao,

Peking University Third Hospital,

China

Reviewed by:

Hang Lin,

University of Pittsburgh, United States

Gianandrea Pasquinelli,

University of Bologna, Italy

${ }^{*}$ Correspondence:

Lianqi Yan

yanlianqi@126.com

Ming Pei

mpei@hsc.wvu.edu

orcid.org/0000-0001-5710-3578

Specialty section:

This article was submitted to

Stem Cell Research,

a section of the journal

Frontiers in Cell and Developmental

Biology

Received: 16 August 2020 Accepted: 12 October 2020

Published: 29 October 2020

Citation:

Lu Z, Zhou S, Vaida J, Gao G, Stewart A, Parenti J, Yan L and Pei $M$ (2020) Unfavorable Contribution of a

Tissue-Engineering Cartilage Graft to Osteochondral Defect Repair in Young Rabbits.

Front. Cell Dev. Biol. 8:595518. doi: 10.3389/fcell.2020.595518

\section{Unfavorable Contribution of a} Tissue-Engineering Cartilage Graft to Osteochondral Defect Repair in Young Rabbits

\author{
Zhihua Lu',2, Sheng Zhou', Justin Vaida', Gongming Gao', Amanda Stewart', \\ Joshua Parenti' ${ }^{1}$ Lianqi Yan ${ }^{2 *}$ and Ming Pei ${ }^{1,3 *}$
}

1 Stem Cell and Tissue Engineering Laboratory, Department of Orthopaedics, West Virginia University, Morgantown, WV, United States, ${ }^{2}$ Department of Orthopedics, Clinical Medical College of Yangzhou University, Subei People's Hospital of Jiangsu Province, Yangzhou, China, ${ }^{3}$ WVU Cancer Institute, Robert C. Byrd Health Sciences Center, West Virginia University, Morgantown, WV, United States

A stem cell-based tissue-engineering approach is a promising strategy for treatment of cartilage defects. However, there are conflicting data in the feasibility of using this approach in young recipients. A young rabbit model with an average age of 7.7 months old was used to evaluate the effect of a tissue-engineering approach on the treatment of osteochondral defects. Following in vitro evaluation of proliferation and chondrogenic capacity of infrapatellar fat pad-derived stem cells (IPFSCs) after expansion on either tissue culture plastic (TCP) or decellularized extracellular matrix (dECM), a premature tissue construct engineered from pretreated IPFSCs was used to repair osteochondral defects in young rabbits. We found that dECM expanded IPFSCs exhibited higher proliferation and chondrogenic differentiation compared to TCP expanded cells in both pellet and tissue construct culture systems. Six weeks after creation of bilateral osteochondral defects in the femoral trochlear groove of rabbits, the Empty group (left untreated) had the best cartilage resurfacing with the highest score in Modified O'Driscoll Scale (MODS) than the other groups; however, this score had no significant difference compared to that of 15-week samples, indicating that young rabbits stop growing cartilage once they reach 9 months old. Interestingly, implantation of premature tissue constructs from both dECM and TCP groups exhibited significantly improved cartilage repair at 15 weeks compared to those at six weeks (about 9 months old), indicating that a tissue-engineering approach is able to repair adult cartilage defects. We also found that implanted pre-labeled cells in premature tissue constructs were undetectable in resurfaced cartilage at both time points. This study suggests that young rabbits (less than 9 months old) might respond differently to the classical tissue-engineering approach that is considered as a potential treatment for cartilage defects in adult rabbits.

Keywords: young rabbit, osteochondral defect, tissue engineering, decellularized extracellular matrix, infrapatellar fat pad-derived stem cell 


\section{INTRODUCTION}

Articular cartilage holds a limited capacity for self-healing due to a shortage of blood supply. Several surgical methods are available for the treatment of cartilage damage, including arthroscopic debridement, microfracture, and osteochondral transplantation; (Willers et al., 2003) however, none can consistently reproduce normal hyaline cartilage (Smith et al., 2005). As an alternative treatment, stem cell-based tissue engineering has been validated as a promising approach to reconstitute cartilage defects (Nukavarapu and Dorcemus, 2013). Seed cells and scaffolds are two important parameters for the success of a tissue-engineering strategy. Increasing data indicate the advantages of infrapatellar fat pad (IPFP)-derived stem cells (IPFSCs) as a stem cell source due to strong proliferation capacities and multilineage differentiation potentials, particularly for cartilage engineering and regeneration (Sun et al., 2018; Wang T. et al., 2020). Among the candidate scaffold materials, polylactic-co-glycolic acid (PLGA) is one of the most widely used biodegradable polymers, owing to its prominent advantages such as maneuverability of degradation rates and outstanding processability (Uematsu et al., 2005). Therefore, in this study, IPFSCs were chosen as seed cells to grow on PLGA scaffolds.

Cell expansion on a two-dimensional (2D) culture substrate often causes stem cell senescence (Li and Pei, 2012). Evidence indicates that decellularized extracellular matrix (dECM), a three-dimensional (3D) culture system, can efficiently rejuvenate expanded stem cells in both proliferation and chondrogenic differentiation ( $\mathrm{Li}$ and Pei, 2010; Pei et al., 2011; Pei, 2017). A previous report successfully utilized dECM expanded synovium-derived stem cells in the treatment of partialthickness cartilage defects in a minipig model via intraarticular injection (Pei et al., 2013). Given that a stem cell-based tissue-engineering approach exhibits a promising strategy to overcome the challenge of tissue defects in elderly recipients, (Uematsu et al., 2005; Han et al., 2008) there are few reports available to determine the feasibility of this approach in cartilage repair in young recipients, considering that older transplant recipients exhibited differently from young recipients in some biological aspects such as in immunosenescence (Colvin et al., 2017). Moreover, there is no consensus on skeletally mature rabbit age with a range from four to nine months old (Masoud et al., 1986; Wei et al., 1997; Wei and Messner, 1999; Rudert, 2002; Reinholz et al., 2004; Hoemann et al., 2007; Hunziker et al., 2007; Pei et al., 2009; Isaksson et al., 2010). In this study, a rabbit model (between 7.5-8 months old) considered as skeletally mature (Masoud et al., 1986; Gilsanz et al., 1988; Newman et al., 1995) was used to evaluate whether articular cartilage became mature and whether a tissue-engineering approach benefited the treatment of osteochondral defects. We hypothesized that a young rabbit (less than 9 months old) does not have mature cartilage and may not respond to a tissueengineering approach for cartilage repair the same as an adult rabbit does.

\section{MATERIALS AND METHODS}

\section{Experimental Design}

Following isolation of IPFSCs from rabbit IPFP, both in vitro and in vivo studies were designed (Figure 1). In the in vitro study (Figure 2), IPFSCs were evaluated in cell proliferation and chondrogenic differentiation (3D culture systems - both pellets and PLGA tissue constructs) by comparing the influence of (1) dECM expansion with tissue culture plastic (TCP) as a control and (2) lentivirus transduction with non-transduction as a control. In the in vivo study (Figures 3-8), after creation of osteochondral defects, four groups were designed: Empty group (left untreated), PLGA group (filled with PLGA alone), TCP group (filled with 20-day-cartilage grafts using TCP expanded IPFSCs), and dECM group (filled with 20-day-cartilage grafts using dECM expanded IPFSCs). Histological evaluation was quantified for cartilage resurfacing of osteochondral defects (Tables 1-3) and implanted cells were tracked using both immunofluorescence microscopy and immunohistochemical staining for green fluorescence protein (GFP) (Figure 8).

\section{IPFSC Isolation and Culture}

This animal study was approved by the Institutional Animal Care and Use Committee. Infrapatellar fat pads from four New Zealand White (NZW) rabbits were used to collect stem cells (IPFSCs) after a sequential digestion using $0.1 \%$ trypsin (Roche, Indianapolis, IN) for $30 \mathrm{~min}$ and $0.1 \%$ collagenase $\mathrm{P}$ (Roche) for $2 \mathrm{~h}$ to release cells. The stemness of IPFSCs was characterized in both human ( $\mathrm{He}$ and Pei, 2013; Pizzute et al., 2016; Wang et al., 2019; Wang Y. M. et al., 2020) and rabbit donors (Wang T. et al., 2020). The pooled IPFSCs were cultured in growth medium [Minimum Essential Medium-Alpha Modification ( $\alpha \mathrm{MEM}$ ) containing 10\% fetal bovine serum (FBS), $100 \mathrm{U} / \mathrm{mL}$ penicillin, $100 \mu \mathrm{g} / \mathrm{mL}$ streptomycin, and $0.25 \mu \mathrm{g} / \mathrm{mL}$ fungizone (Invitrogen, Carlsbad, CA)] at $37^{\circ} \mathrm{C}$ in a humidified $21 \% \mathrm{O}_{2}$ and $5 \% \mathrm{CO}_{2}$ incubator. The medium was changed every three days.

\section{IPFSC Labeling}

Passage 2 rabbit IPFSCs were transduced with lentivirus carrying GFP in the presence of $4 \mu \mathrm{g} / \mathrm{mL}$ of protamine sulfate (MilliporeSigma, Burlington, MA). Twenty-four hours later, the medium was replaced with $\alpha$ MEM with $10 \% \mathrm{FBS}$ and $2 \mu \mathrm{g} / \mathrm{mL}$ of puromycin (MilliporeSigma) for cell screening. Passage 5 rabbit IPFSCs labeled with GFP were collected for the in vivo study.

\section{dECM Preparation}

dECM was prepared by following a protocol described in a previous report ( $\mathrm{Li}$ and Pei, 2018). Briefly, TCP was treated with $0.2 \%$ gelatin (MilliporeSigma), $1 \%$ glutaraldehyde (MilliporeSigma), and $1 \mathrm{M}$ ethanolamine (MilliporeSigma). Passage 2 IPFSCs at $100 \%$ confluence on pre-coated TCP were treated with $250 \mu \mathrm{M}$ of L-ascorbic acid phosphate (Wako Chemicals, Richmond, VA) for seven days (Pizzute et al., 2016) followed by an incubation with extraction buffer $(0.5 \%$ Triton X-100 containing $20 \mathrm{mM}$ ammonium 


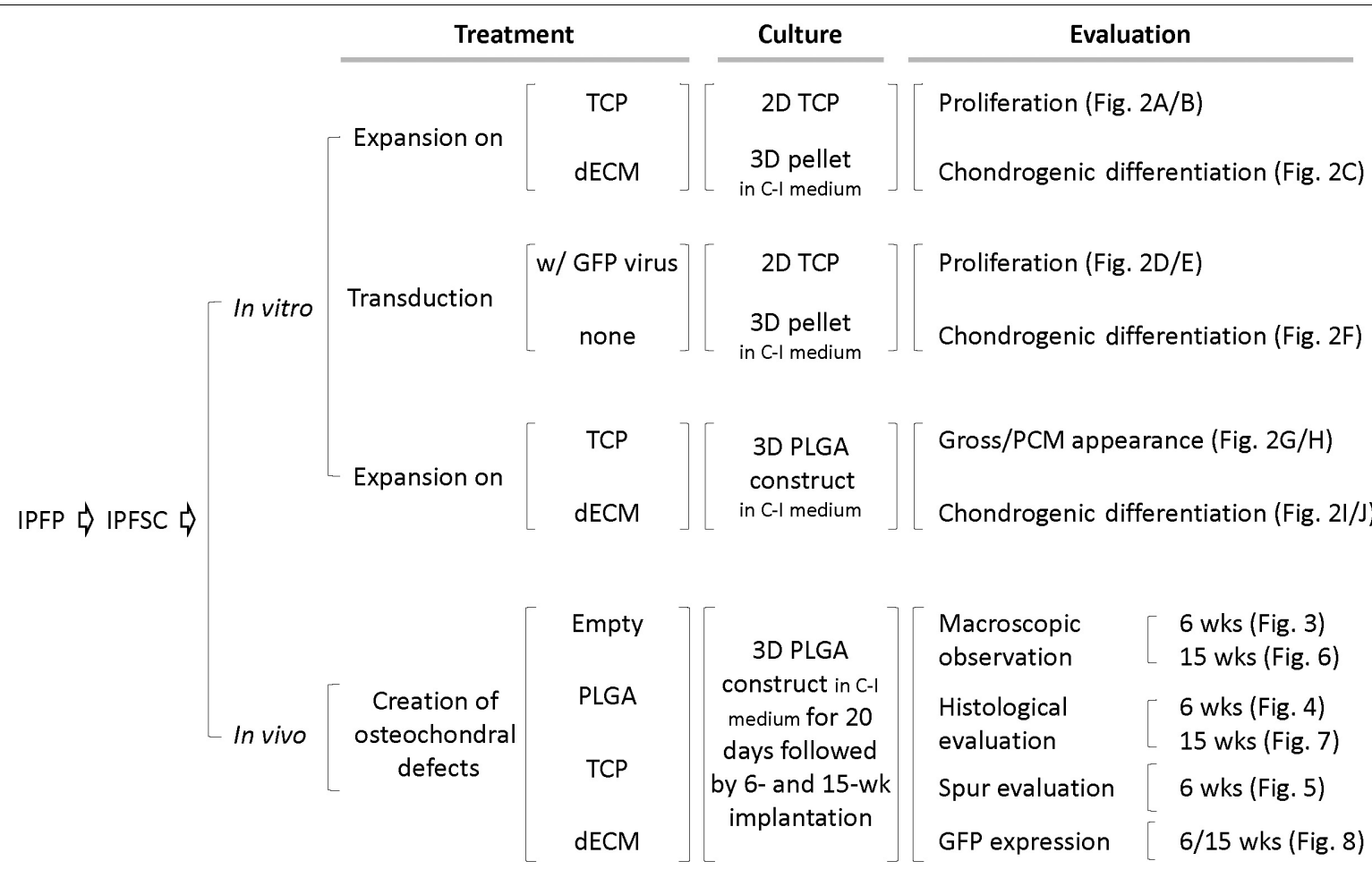

FIGURE 1 | Schematic diagram of experimental design. Abbreviation: C-I - chondrogenic induction; dECM - decellularized extracellular matrix; GFP - green fluorescence protein; PCM - phase contrast microscopy; TCP - tissue culture plastic.

hydroxide). After cells were removed, dECM was stored in phosphate buffered solution (PBS) containing $100 \mathrm{U} / \mathrm{mL}$ penicillin, $100 \mu \mathrm{g} / \mathrm{mL}$ streptomycin, and $0.25 \mu \mathrm{g} / \mathrm{mL}$ fungizone at $4^{\circ} \mathrm{C}$ until use.

\section{Three Experiments Were Designed as Follows}

1) A comparison of $\mathrm{AECM}$ and TCP expanded IPFSCs in proliferation and chondrogenic differentiation: Passage 5 IPFSCs were expanded on TCP and dECM for one passage followed by a 30-day chondrogenic induction in a pellet culture system. Cell morphology and relative 5-Ethynyl-2'-deoxyuridine (EdU) incorporation were evaluated for proliferation capacity. A serumfree chondrogenic medium consisted of high-glucose Dulbecco's modified Eagle's medium, $100 \mathrm{nM}$ dexamethasone, $40 \mu \mathrm{g} / \mathrm{mL}$ proline, $0.1 \mathrm{mM} \mathrm{L}$-ascorbic acid-2-phosphate, $100 \mathrm{U} / \mathrm{mL}$ penicillin, $100 \mu \mathrm{g} / \mathrm{mL}$ streptomycin, $0.25 \mu \mathrm{g} / \mathrm{mL}$ fungizone, and $1 \times \mathrm{ITS}^{\mathrm{TM}}$ Premix (Corning, Bedford, MA) with the addition of $10 \mathrm{ng} / \mathrm{mL}$ transforming growth factor beta3 (TGF- $\beta 3$; PeproTech, Rocky Hill, NJ). Real-time quantitative PCR (RT-qPCR) analysis was used to assess mRNA levels of chondrogenic markers [SOX9 (SRY-box 9), $A C A N$ (aggrecan), and COL2A1 (type II collagen alpha I chain)] in expanded cells and chondrogenic pellets (day 0,14 , and 30 ).
Following our previously published methods, (Pei et al., $2002 a, b) 1.3 \times 10^{6}$ cells from either TCP or dECM expansion were seeded on one $5 \mathrm{~mm}$ diameter $\times 2 \mathrm{~mm}$ thickness PLGA mesh (Synthecon, Houston, TX) in a spinner flask. After incubation for $72 \mathrm{~h}$ to allow cell attachment, the cellscaffold constructs were transferred into six-well plates and cultured in a serum-free chondrogenic medium in a standard incubator $\left(5 \% \mathrm{CO}_{2}\right.$ and $\left.21 \% \mathrm{O}_{2}\right)$ for ten days and subsequently in a hypoxia incubator $\left(5 \% \mathrm{CO}_{2}\right.$ and $\left.5 \% \mathrm{O}_{2}\right)$ for ten days (Li et al., 2011; Galeano-Garces et al., 2017). Constructs were harvested at day 20 for chondrogenic evaluation [SOX9, ACAN, COL2A1, and COL10A1 (type X collagen alpha1)] using RTqPCR analyses.

Cell proliferation was evaluated using the Click-iT ${ }^{\mathrm{TM}}$ EdU Alexa Fluor ${ }^{\mathrm{TM}} 647$ Flow Cytometry Assay Kit (Invitrogen). IPFSCs $\left(5 \times 10^{5}\right)$ were incubated with $10 \mu \mathrm{M}$ EdU for $18 \mathrm{~h}$ followed by staining as per manufacturer's protocol. Briefly, cells were incubated with Click-i $\mathrm{T}^{\mathrm{TM}}$ fixative for $15 \mathrm{~min}$ in the dark followed by washing with $1 \%$ bovine serum albumin (BSA)-PBS and then resuspended in $1 \times$ Click$\mathrm{iT}^{\mathrm{TM}}$ saponin-based permeabilization buffer. Following staining in labeling cocktail for $30 \mathrm{~min}$, cells were analyzed with a FACS Calibur (BD Biosciences, San Jose, CA) and data analyzed using FCS Express software package (De Novo Software, Pasadena, CA).

For RT-qPCR, total RNA was extracted from tissue constructs $(\mathrm{n}=4)$ using TRIzol $^{\circledR}$ (Life Technologies, Carlsbad, CA) as per manufacturer's protocol. Subsequently, cDNA was synthesized 
A
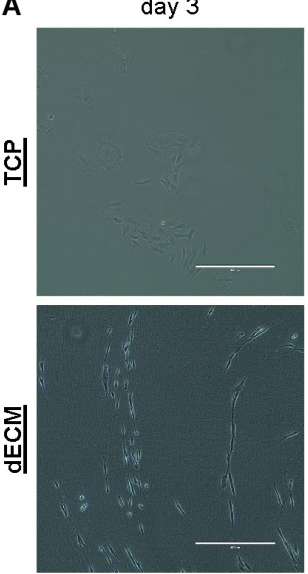

D
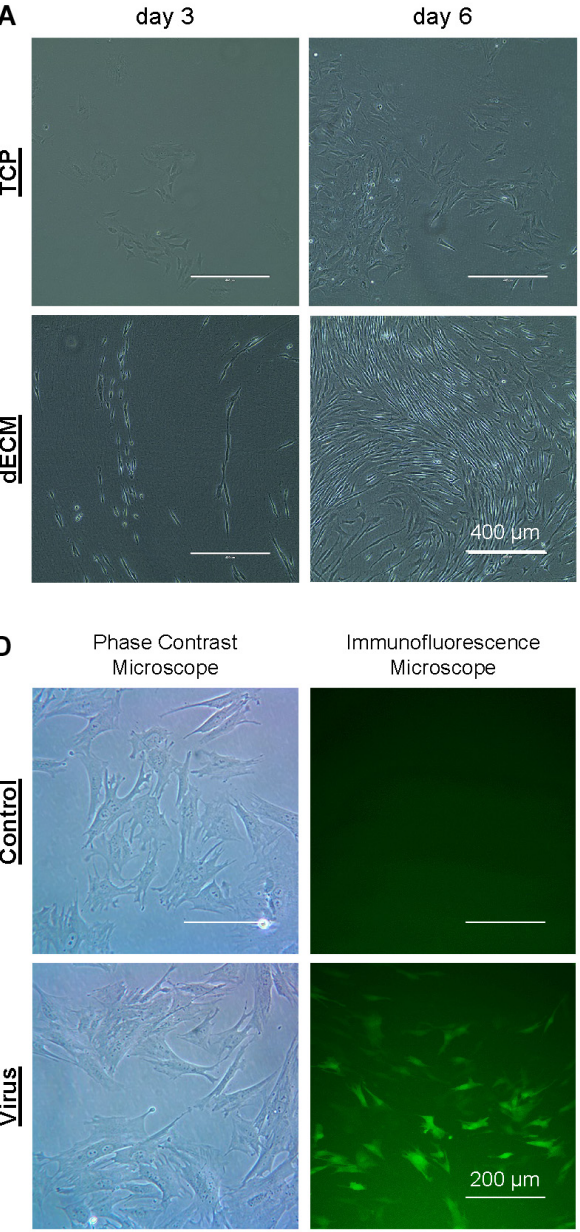

Immunofluorescence Microscope

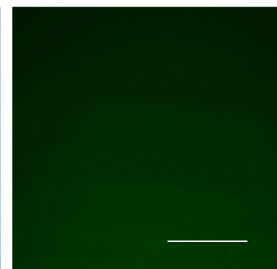

E

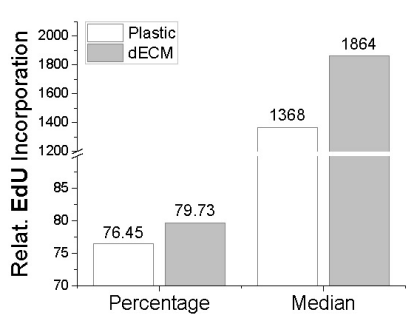

C
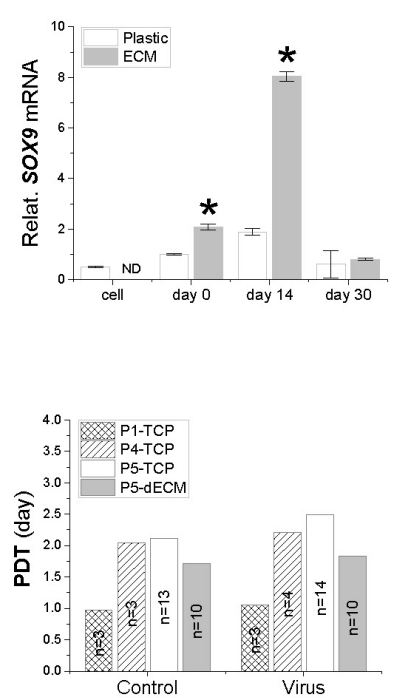
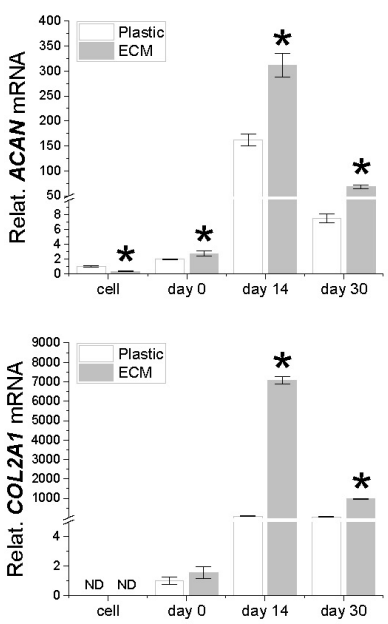

$\mathbf{F}$

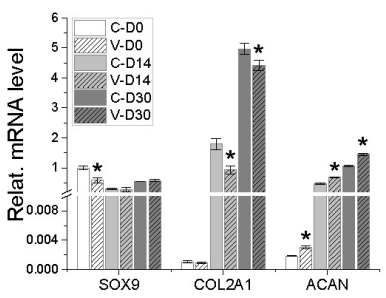

G

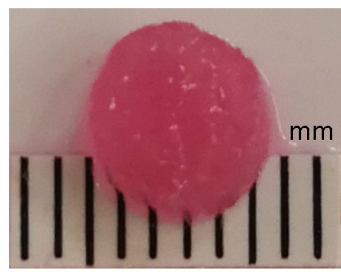

H

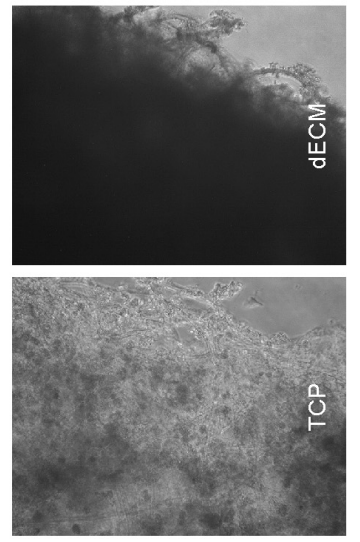

\section{I}

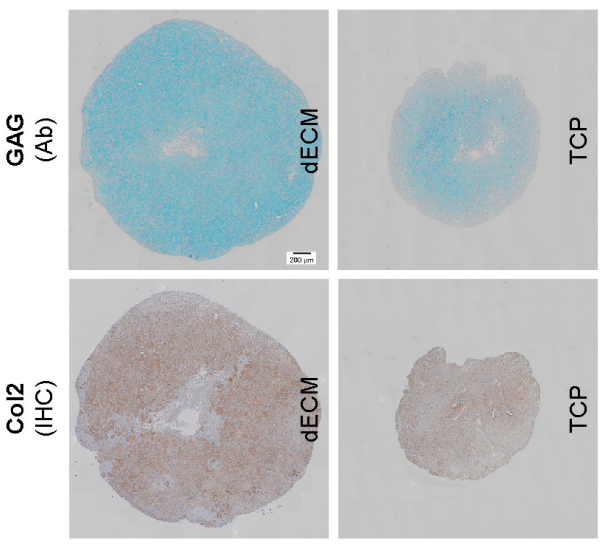

$\mathbf{J}$

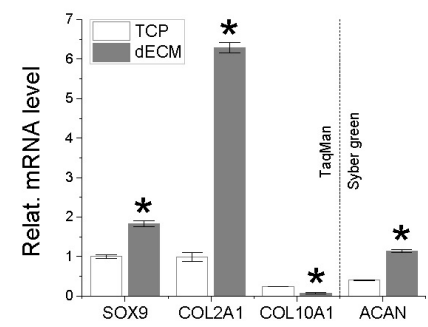

FIGURE 2 | A comparison of IPFSCs and their capacity for proliferation and chondrogenic differentiation following expansion on either dECM or TCP (A-C) and with or without lentivirus transduction (D-F) as well as of premature tissue constructs seeded with $2.2 \times 10^{6}$ IPFSCs after expansion on dECM or TCP (G-K). (A) Cell morphology of IPFSCs after 3- and 6-day culture on either dECM or TCP; Scale bar: $400 \mu \mathrm{m}$; (B) relative EdU incorporation of dECM or TCP expanded 


\section{FIGURE 2 | Continued}

IPFSCs $\left(5 \times 10^{5}\right)$ measured by flow cytometry, and (C) RT-qPCR evaluation of expression level of chondrogenic marker genes (SOX9, ACAN, and COL2A1) in dECM or TCP expanded IPFSCs $(n=4)$ after 30-day chondrogenic induction in a pellet culture system. ${ }^{*} p<0.05$ as compared to the control group (TCP). (D) Transduction efficiency in puromycin screened IPFSCs visualized by immunofluorescence and phase contrast microscopy; Scale bar: $200 \mu \mathrm{m}$; (E) population doubling time (PDT) in IPFSCs with or without transduction following dECM and TCP expansion; and (F) expression of chondrogenic marker genes (SOX9, ACAN, and COL2A1) via RT-qPCR in IPFSCs ( $n=4$ ) with ("V") or without ("C") transduction after 30-day chondrogenic induction in a pellet culture system. * $p$ < 0.05 as compared to the control group (non-virus transduction). (G) A representative photo of a two-week tissue construct; (H) phase contrast microscopy of 20-day tissue constructs (dECM or TCP expanded IPFSCs grown on PLGA mesh); (I) histological evaluation of 20-day tissue constructs using Alcian blue staining (Ab) for sulfated GAGs and immunohistochemical staining (IHC) for type II collagen; Scale bar: $200 \mu \mathrm{m}$; (J) expression of chondrogenic marker genes (SOX9, ACAN, COL2A1, and COL10A1) via RT-qPCR analysis in dECM or TCP expanded IPFSCs $(n=4)$ after 20 -day chondrogenic induction in six-well plates. ${ }^{*} p<0.05$ as compared to the control group (TCP).
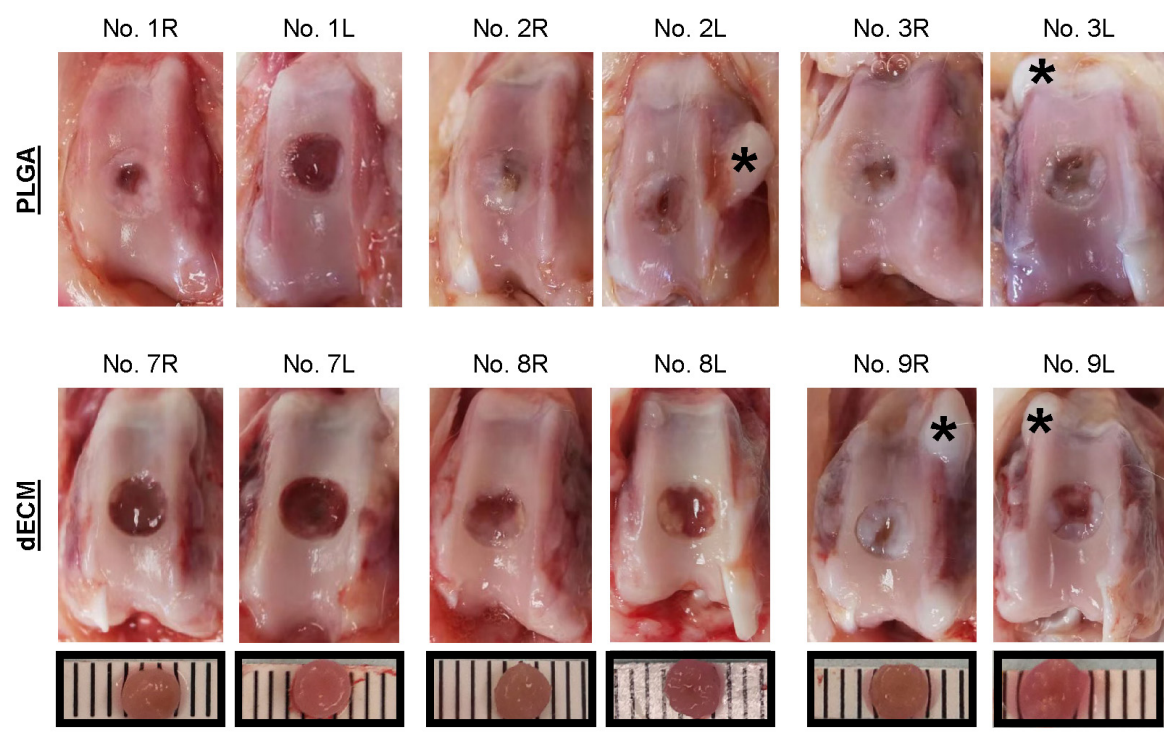

No. $7 \mathrm{~L}$

No. $8 \mathrm{R}$

No. $8 \mathrm{~L}$
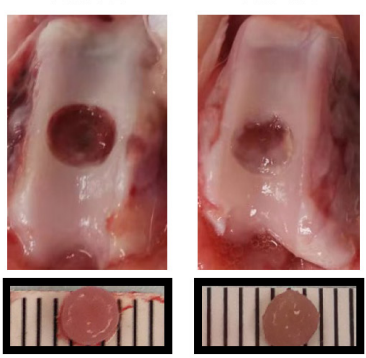

No. 9R

No. 9L
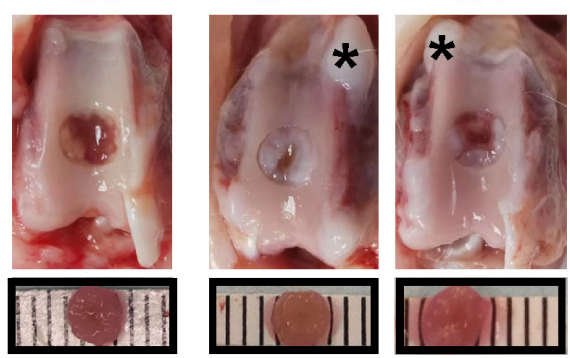

No. $10 \mathrm{R}$

No. $10 \mathrm{~L}$

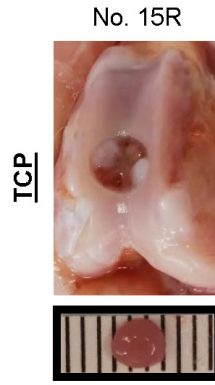

No. $15 \mathrm{~L}$

No. $16 \mathrm{R}$

No. $16 \mathrm{~L}$

No. $17 \mathrm{R}$

No. 17L
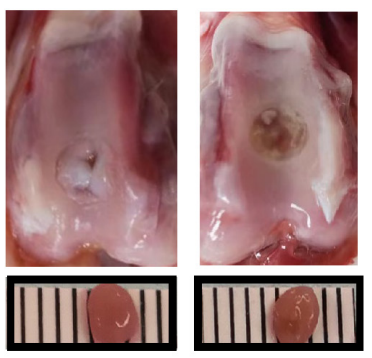

No. $18 \mathrm{R}$

No. 18L
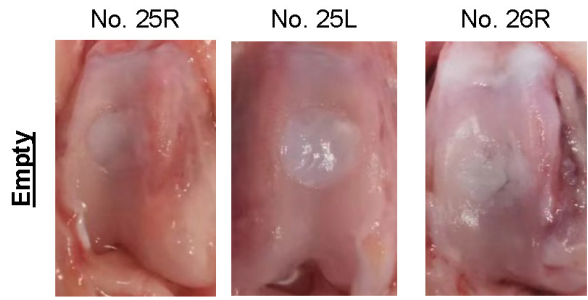

No. $26 \mathrm{~L}$

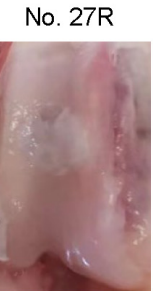

No. $27 \mathrm{~L}$
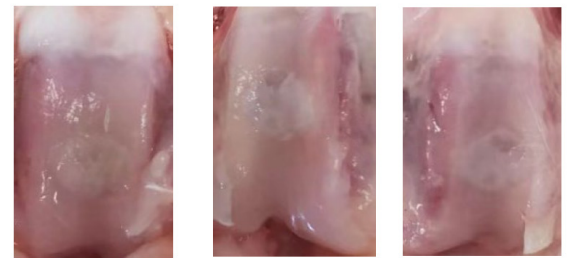

FIGURE 3 | Macroscopic observation of six-week osteochondral defects repaired with PLGA mesh alone (PLGA; $n=3$ rabbits/6 knees), tissue constructs developed from dECM expanded IPFSCs (dECM; $n=4$ rabbits $/ 8$ knees) or TCP expanded cells (TCP; $n=4$ rabbits $/ 8$ knees), or left untreated (Empty; $n=3$ rabbits/6 knees). Scale bar: $1 \mathrm{~mm}$.

from mRNA by reverse transcriptase using a High-Capacity cDNA Archive Kit (Thermo Fisher Scientific, Waltham, MA). Primers of the chondrogenic marker gene [ACAN (forward GCTACGGAGACAAGGATGAGTTC and reverse CGTAAAAGACCTCACCCTCCAT)] and endogenous control gene GAPDH (glyceraldehyde-3-phosphate dehydrogenase; 

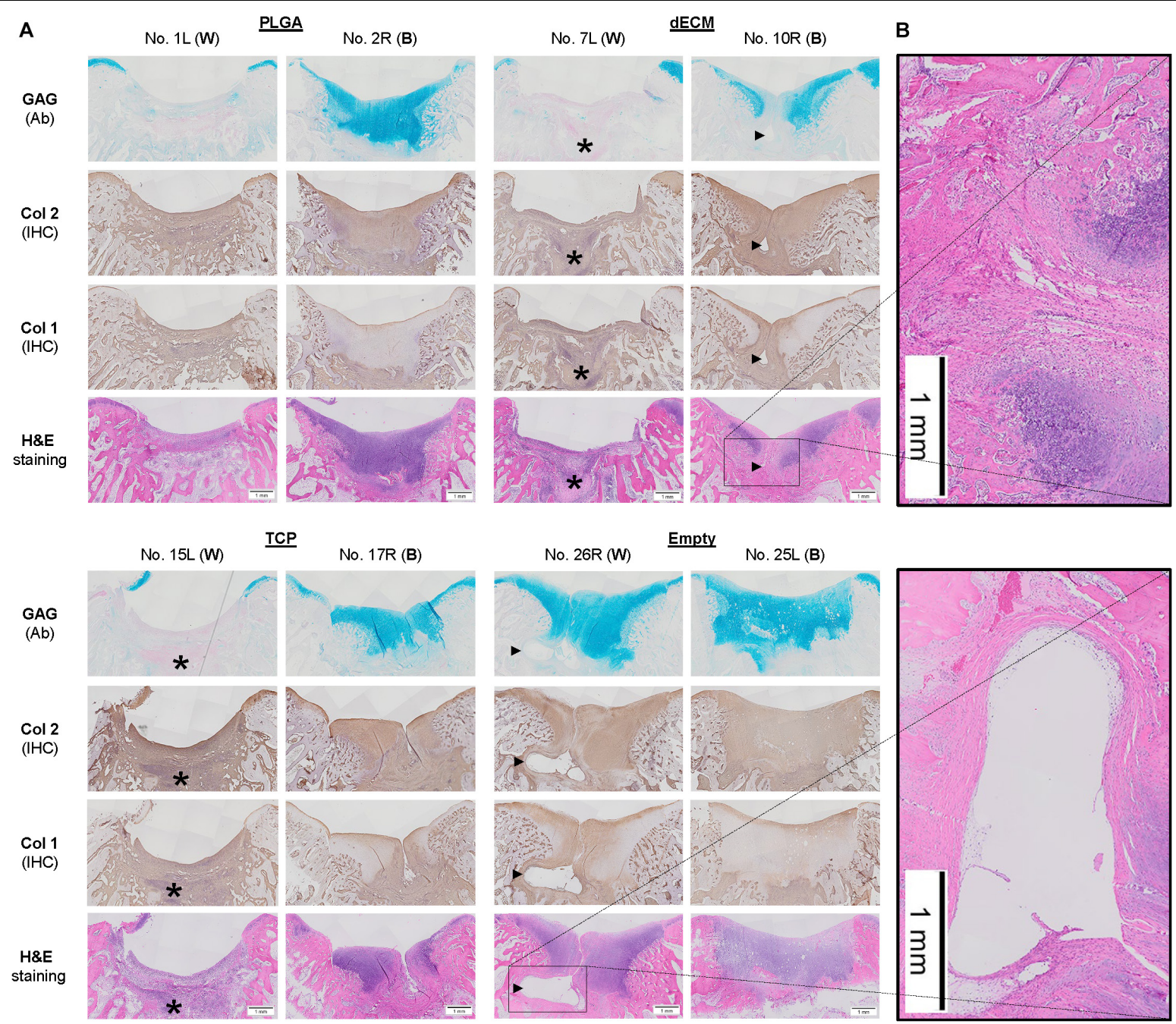

FIGURE 4 | Histological evaluation of six-week osteochondral defects repaired with PLGA mesh alone (PLGA; $n=6$ knees), tissue constructs developed from dECM expanded IPFSCs (dECM; $n=8$ knees) or TCP expanded cells (TCP; $n=8$ knees), or left untreated (Empty; $n=6$ knees) using Alcian blue staining (Ab) for sulfated GAGs, H\&E staining for the intact tidemark, and immunohistochemical staining (IHC) for types I and II collagen (Col 1 and Col 2). (A) Two representative cartilage resurfacings were chosen from each group to serve as the best repair ("B") including rabbit No. 2R/10R/17R/25L or the worst repair ("W") including rabbit No. $1 \mathrm{~L} / 7 \mathrm{~L} / 15 \mathrm{~L} / 26 \mathrm{R}$. Arrows $(\downarrow)$ indicate location of subchondral bone cysts and the asterisk (*) indicates mononuclear cells. (B) Bone cysts were shown at higher magnification in H\&E staining. Scale bar: $1 \mathrm{~mm}$.

forward TTCCACGGCACGGTCAAGGC and reverse GGGCAC CAGCATCACCCCAC) were designed by Integrated DNA Technologies (IDT, Coralville, IA) as a $\mathrm{SYBR}^{\oplus}$ green gene expression assay using their PCR primer design tool. Primers for chondrogenic-related genes [SOX9 (Assay ID Oc04096872_m1), COL2A1 (Assay ID Oc03396132_g1), and COL10A1 (Assay ID Oc04097225_s1)] were used in a $\operatorname{TaqMan}^{\circledR}$ gene expression assay from Applied Biosystems (Foster City, CA). RTqPCR was performed using the iCycler $\mathrm{iQ}^{\mathrm{TM}}$ Multicolor RT-PCR Detection.

2) A comparison of IPFSCs with or without lentivirus transduction in proliferation and chondrogenic differentiation: Passage 5 IPFSCs with or without transduction of lentivirus vector carrying GFP
(pRSC-SFFV-Luciferase-E2A-Puro-E2A-GFP-wpre) were evaluated for potential influence of viral transduction on cell proliferation and chondrogenic capacity. Immunofluorescence microscopy was used to demonstrate successful transduction following puromycin screening. TCP expanded IPFSCs with or without transduction were counted in T175 TCP $(\mathrm{n}=3 \sim 14)$ using a hemocytometer from passage 1 to 5 along with dECM expanded cells at passage 5 with or without transduction. Cell population doubling time (PDT) was then calculated as "PDT $=\mathrm{T}^{*} \log$ (2)/[log $\left.\left(\mathrm{N}_{1}\right)-\log \left(\mathrm{N}_{0}\right)\right]$ ", where $\mathrm{T}$ represents incubation time, $\mathrm{N}_{1}$ for harvesting cell number, and $\mathrm{N}_{0}$ for plating cell number. Expanded IPFSCs $\left(4 \times 10^{5}\right.$ cells) with or without transduction at passage 5 were pelleted by centrifugation in a $15-\mathrm{ml}$ polypropylene tube at 1200 revolutions per 


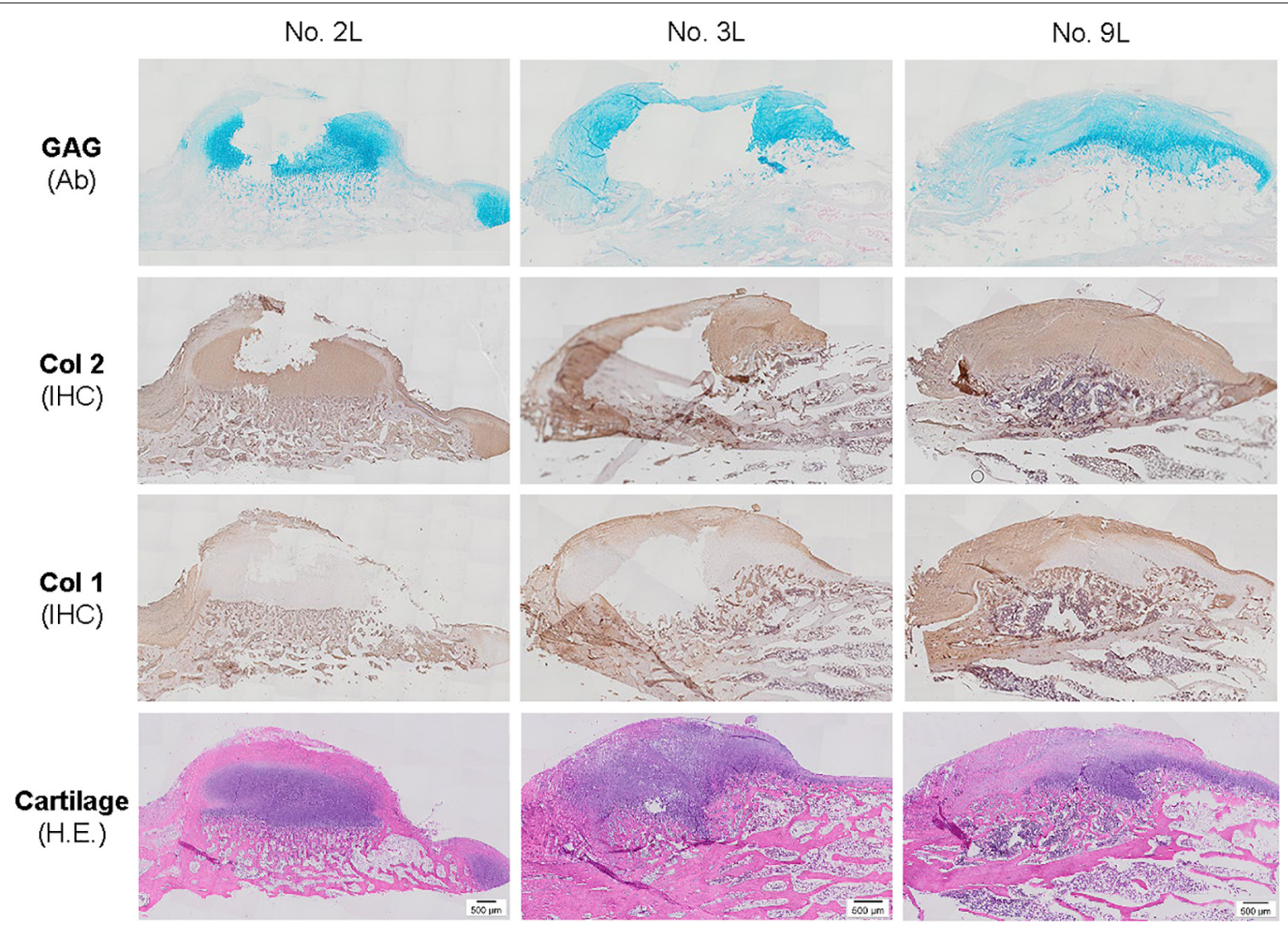

FIGURE 5 | Histological evaluation of bone spurs in 6-week cartilage resurfacing using Alcian blue staining (Ab) for sulfated GAGs, H\&E staining for cartilage tissue and immunohistochemical staining $(\mathrm{IHC})$ for types I and II collagen (Col 1 and Col 2). Scale bar: $500 \mu \mathrm{m}$.

minute for $7 \mathrm{~min}$. Following overnight incubation (day 0 samples), pellets were grown in a serum-free chondrogenic medium for up to 30 days. Pellets were harvested at day 0 , 14, and 30 for evaluation of chondrogenic marker genes (SOX9, COL2A1, and ACAN) via RT-qPCR.

3) Using GFP-labeled IPFSCs with or without dECM expansion to develop premature tissue constructs to repair osteochondral defects in young rabbits. GFPlabeled passage 6 IPFSCs $\left(2.2 \times 10^{6}\right.$ cells $)$ with or without dECM expansion were seeded in $5 \mathrm{~mm}$ diameter $\times 2 \mathrm{~mm}$ thickness PLGA mesh in a spinner flask for three days, (Pei et al., 2002a,b) followed by culture in six-well plates in the presence of serum-free chondrogenic induction medium in a standard incubator $\left(5 \% \mathrm{CO}_{2}\right.$ and $\left.21 \% \mathrm{O}_{2}\right)$ for ten days and subsequently in a hypoxia incubator $\left(5 \% \mathrm{CO}_{2}\right.$ and $5 \% \mathrm{O}_{2}$ ) for ten days ( $\mathrm{Li}$ et al., 2011; Galeano-Garces et al., 2017). After observation with immunofluorescence microscopy to confirm the presence of a GFP signal, 20day tissue constructs developed from either $\mathrm{AECM}$ or TCP expanded IPFSCs were used to repair osteochondral defects in young rabbits.

Young NZW rabbits ( $\mathrm{n}=28$, female, $2.5-4 \mathrm{~kg}, 235.2 \pm 2.7$ days with an average age of 7.7-months) (Envigo Global Services Inc., Denver, PA) were used in this study. Anesthesia was induced with an intramuscular injection with $5 \mathrm{mg} / \mathrm{kg}$ xylazine (Phoenix Pharmaceutical, St. Joseph, MO) and $35 \mathrm{mg} / \mathrm{kg}$ ketamine (Phoenix Pharmaceutical) and maintained with isofluorane. The patella was dislocated laterally and a $4.76 \mathrm{~mm}$ diameter $\times 2 \mathrm{~mm}$ depth osteochondral defect was created in the patellar groove of the femur in both knees using a custom designed hand drill with a depth stop. Four groups were designated: defects treated with premature tissue constructs developed by either dECM or TCP expanded cells (the AECM group and the TCP group, respectively) ( $\mathrm{n}=16 \mathrm{knees} / 8$ rabbits/group), and PLGA scaffold only (the PLGA group) or left untreated (the Empty group) ( $n=12$ knee/6 rabbits/group). Six weeks and 15 weeks postoperatively, rabbits in each group were euthanized for gross observation and histologic evaluation for cartilage resurfacing.

For macroscopic evaluation, once both knee joints were opened, the defect area of the patellar groove was photographed, and gross examination was performed. Femoral condyles were dissected followed by fixation in $4 \%$ paraformaldehyde in PBS at $4^{\circ} \mathrm{C}$ for three days. Each specimen was decalcified by incubation in $15 \%$ ethylenediaminetetraacetic acid (EDTA)/0.1\% paraformaldehyde solution for six weeks. A $5-\mu \mathrm{m}$ thick section of the grafted area in the coronal plane was stained using Alcian blue (counterstained with fast red) for sulfated 

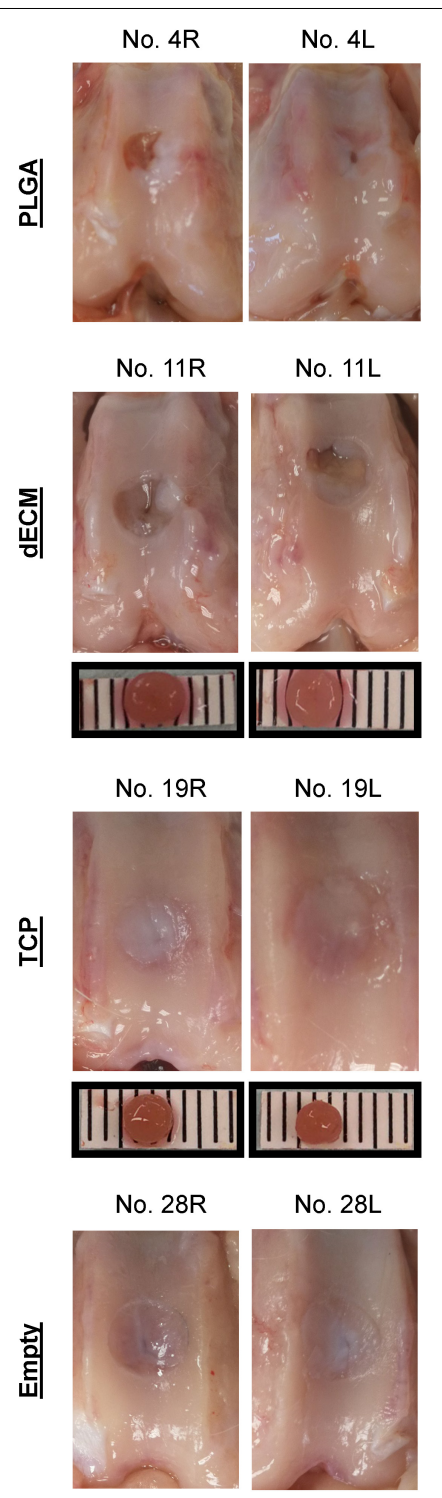

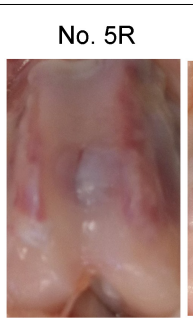

No. $12 \mathrm{R}$

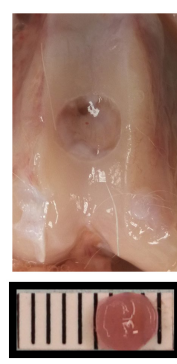

No. 20R

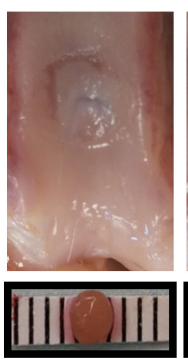

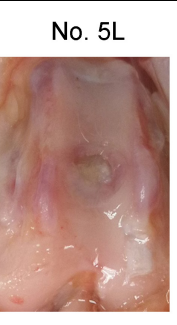

No. $12 \mathrm{~L}$

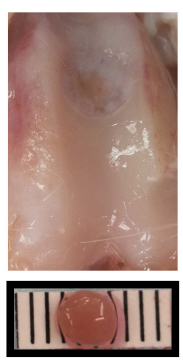

No. 20L

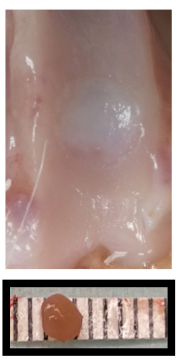

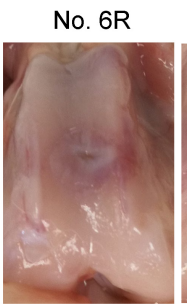

No. $13 R$

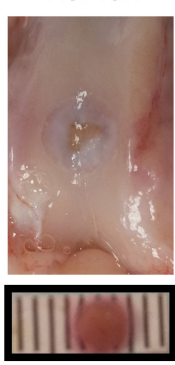

No. $13 \mathrm{~L}$
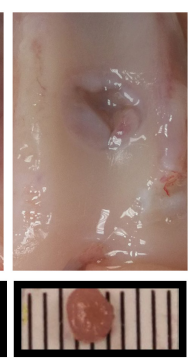

No. $21 R$
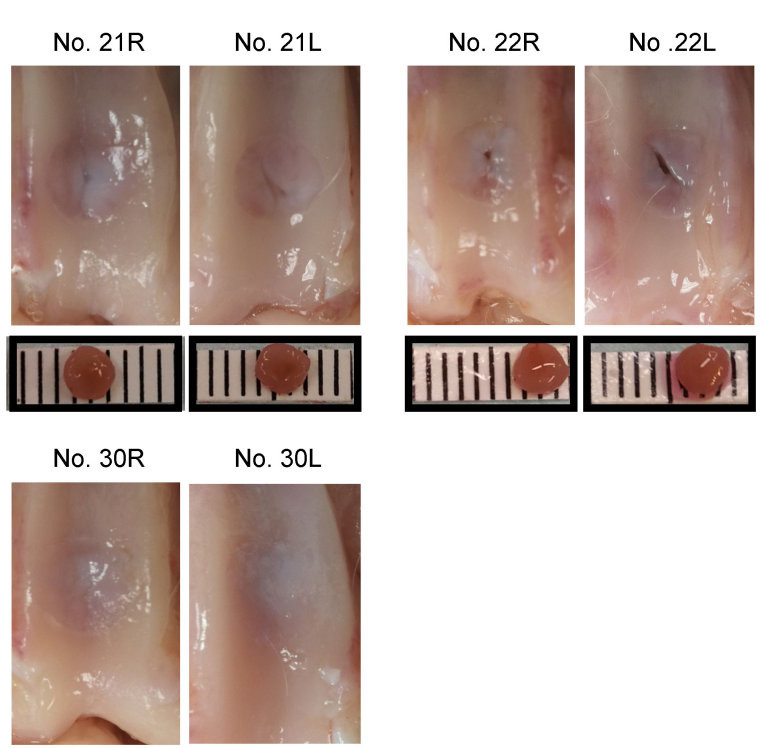

No. $14 \mathrm{R} \quad$ No. $14 \mathrm{~L}$

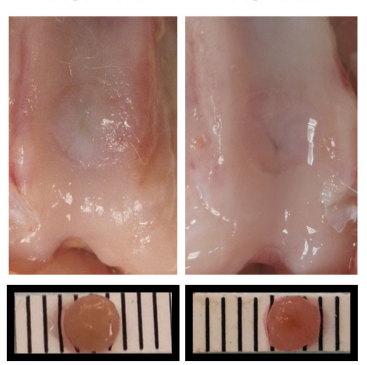

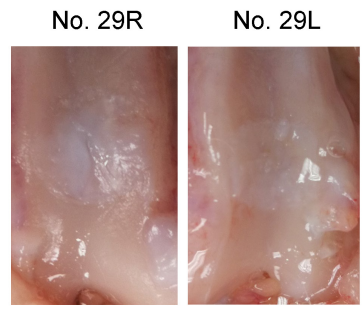

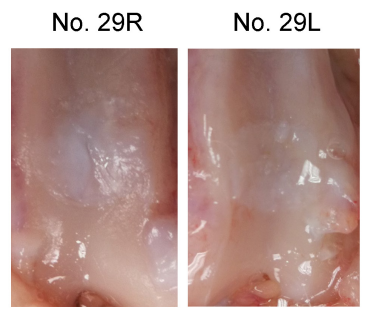

FIGURE 6 | Macroscopic observation of 15-week osteochondral defects repaired with PLGA mesh alone (PLGA; $n=3$ rabbits/6 knees), tissue constructs developed from dECM expanded IPFSCs (dECM; $n=4$ rabbits $/ 8$ knees) or TCP expanded cells (TCP; $n=4$ rabbits $/ 8$ knees), or left untreated (Empty; $n=3$ rabbits/6 knees). Scale bar: $1 \mathrm{~mm}$.

glycosaminoglycans (GAGs) and hematoxylin-eosin staining (H\&E) for identification of the intact tidemark line that separates calcified and non-calcified cartilaginous matrix. For immunohistochemical analysis, $1 \%$ hydrogen peroxide $\left(\mathrm{H}_{2} \mathrm{O}_{2}\right)$ in methanol was used to inactivate endogenous peroxidase activity. Sections were digested with $2 \mathrm{mg} / \mathrm{mL}$ hyaluronidase for $30 \mathrm{~min}$ followed by overnight incubation at $4^{\circ} \mathrm{C}$ with monoclonal mouse antibodies against type I collagen (MilliporeSigma) and type II collagen (Developmental Studies Hybridoma Bank, Iowa City, IA). Sections for GFP detection were treated with citrate unmasking solution for $20 \mathrm{~min}$ followed by overnight incubation at $4^{\circ} \mathrm{C}$ with a monoclonal mouse antibody against GFP (4B10, Cell Signaling Technology, Danvers, MA). After extensive washing with
PBS, sections were incubated with a secondary antibody for $30 \mathrm{~min}$ at room temperature. Immunostaining conducted with Vectastain $^{\circledast} \mathrm{ABC}$ reagent (Vector Laboratories, Burlingame, $\mathrm{CA}$ ) was followed by 3,30-diaminobenzidine (DAB) staining and counterstaining was performed with hematoxylin (Vector Laboratories). Tissue sections were graded by four experts blinded to group assignment using a Modified O'Driscoll Scale (MODS) (Table 1; O’Driscoll et al., 1986; Rutgers et al., 2010; Barron et al., 2015).

\section{Statistical Analysis}

Results from RT-qPCR and histological scoring are presented as mean \pm standard error of the mean; the $t$-test was used to assess data between two groups. All statistical analyses were performed 


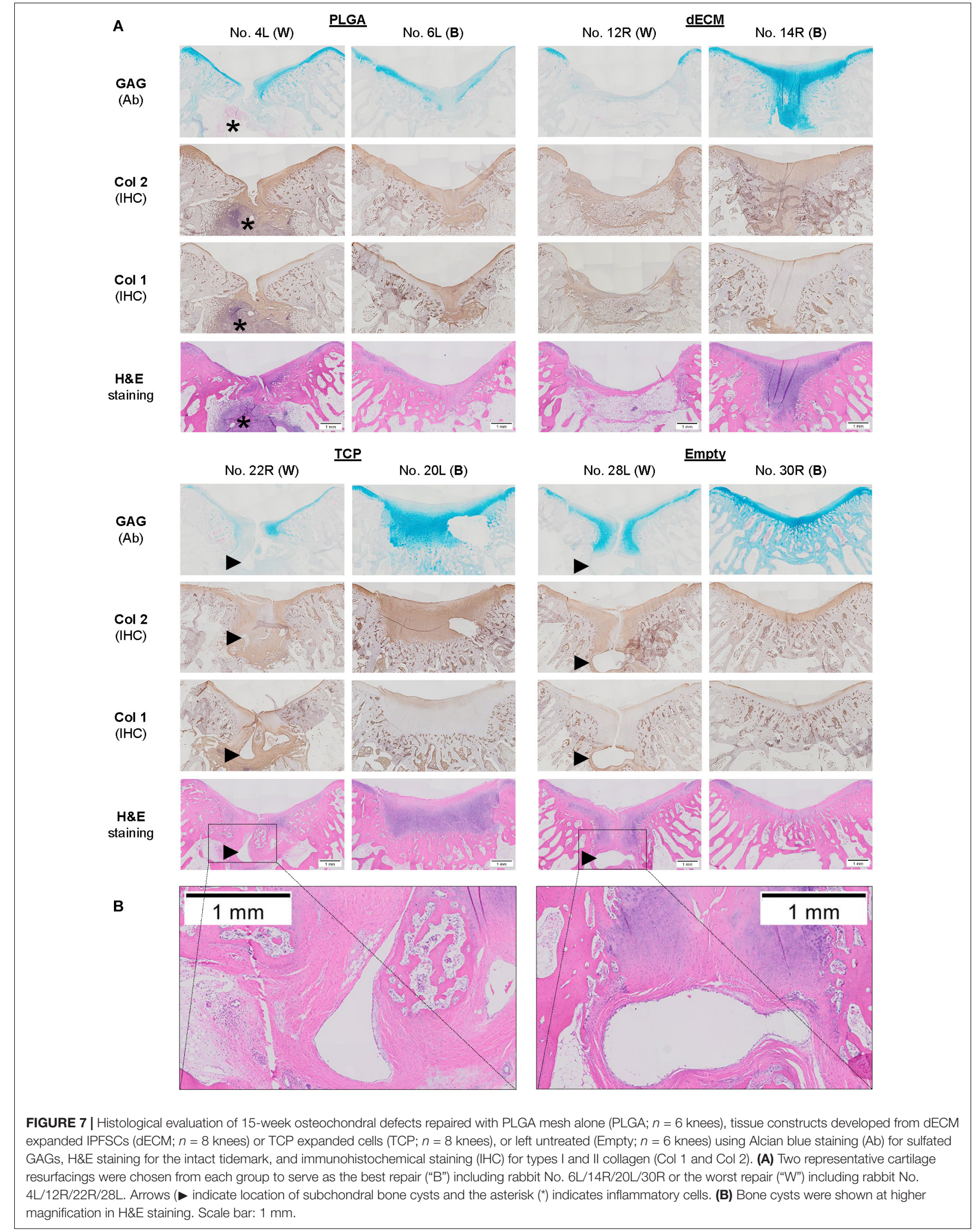



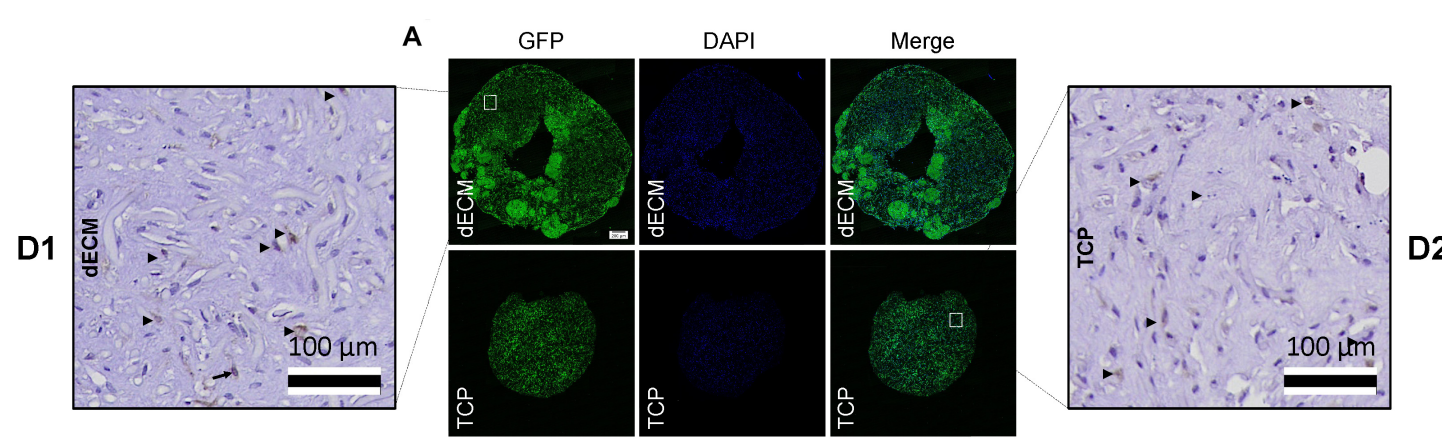

E1

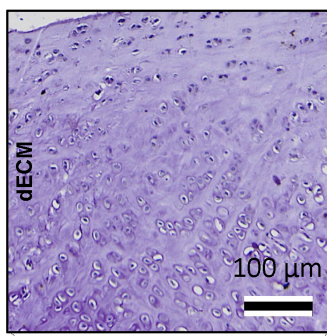

B
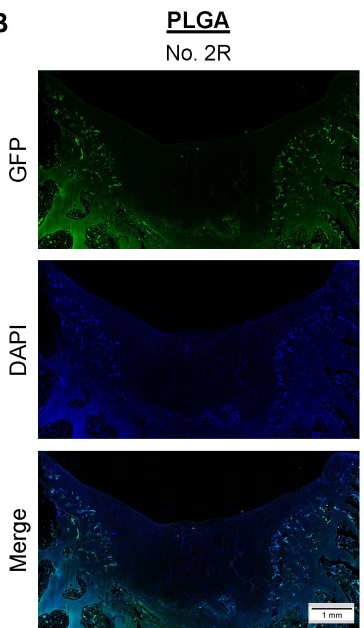

C
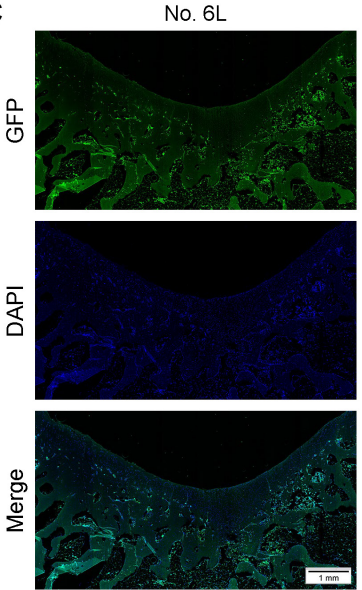

No. $10 \mathrm{R}$
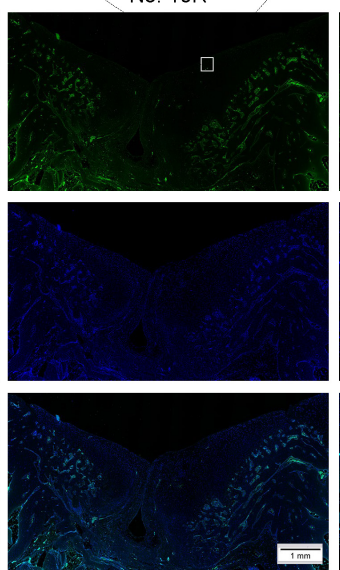

No. $14 \mathrm{R}$
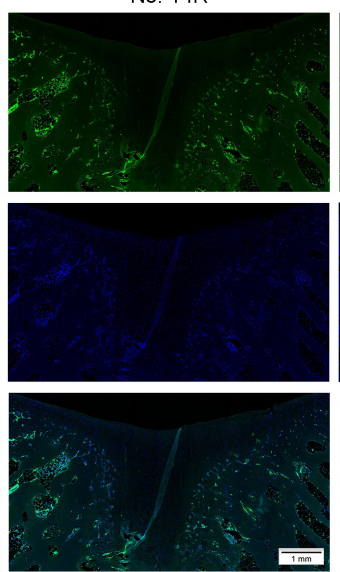

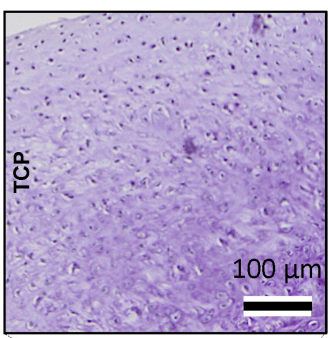

E2
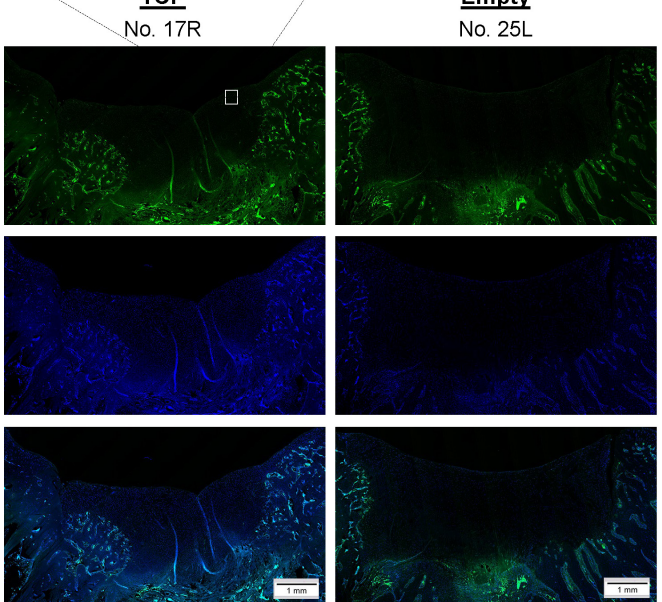

No. $20 \mathrm{~L}$
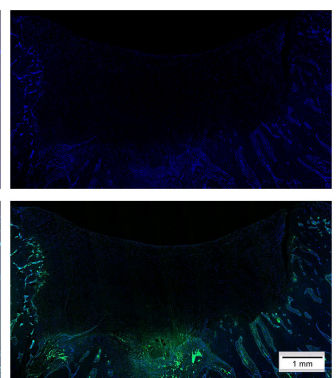

No. 30R
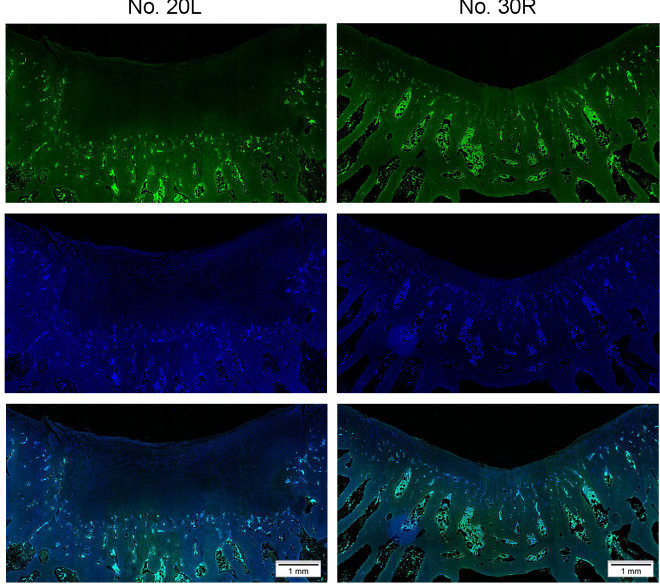

FIGURE 8 | Track of implanted cells labeled with GFP signal. Immunofluorescence of GFP expression in in vitro tissue constructs (Scale bar: $200 \mu$ m) from either dECM or TCP expanded IPFSCs (A), and six-week (B) and 15-week (C) osteochondral defects repaired with PLGA mesh alone (PLGA; $n=6$ knees), tissue constructs developed from dECM expanded IPFSCs (dECM; $n=8$ knees) or TCP expanded cells (TCP; $n=8 \mathrm{knees),} \mathrm{or} \mathrm{left} \mathrm{untreated} \mathrm{(Empty;} n=6$ knees) (Scale bar: $1 \mathrm{~mm}$ ). DAPI served as a counterstain. Immunohistochemical staining using monoclonal antibody showed positive staining (Arrows; constructs (D) but negative staining for in vivo resurfacing cartilage from the tissue construct groups (E). Scale bar: $100 \mu \mathrm{m}$. Hematoxylin served as a counterstain. 
TABLE 1 | Modified O’Driscoll histological scoring system.

\begin{tabular}{|c|c|}
\hline Category & Score \\
\hline \multicolumn{2}{|l|}{ I: Percentage of repair tissue that is hyaline cartilage } \\
\hline $100-125 \%$ & 6 \\
\hline $80-100 \%$ & 8 \\
\hline $60-80 \%$ & 6 \\
\hline $40-60 \%$ & 4 \\
\hline $20-40 \%$ & 2 \\
\hline $0-20 \%$ & 0 \\
\hline \multicolumn{2}{|l|}{ II: Articular surface continuity } \\
\hline Continuous and smooth & 2 \\
\hline Continuous but rough & 1 \\
\hline Discontinuous & 0 \\
\hline \multicolumn{2}{|l|}{ III: Tidemark } \\
\hline Present & 2 \\
\hline Incomplete (degenerative, vessel crossing) & 1 \\
\hline Absent & 0 \\
\hline \multicolumn{2}{|l|}{ IV: Thickness of repair tissue compared to host cartilage } \\
\hline $121-150 \%$ of normal cartilage & 1 \\
\hline $81-120 \%$ of normal cartilage & 2 \\
\hline $51-80 \%$ of normal cartilage & 1 \\
\hline 0-50\% of normal cartilage & 0 \\
\hline \multicolumn{2}{|l|}{ V: Integration of cartilage } \\
\hline Complete (integrated at both sides) & 2 \\
\hline Partial & 1 \\
\hline Poor (not integrated at both sides) & 0 \\
\hline \multicolumn{2}{|l|}{ VI: Degenerated changes in repair tissue } \\
\hline Normal cellularity & 2 \\
\hline Slight to moderate hypocellularity or hypercellularity & 1 \\
\hline Severe hypocellularity or hypercellularity & 0 \\
\hline \multicolumn{2}{|l|}{ VII: Degenerative changes in adjacent cartilage } \\
\hline Normal cellularity, no clusters, no fibrillations & 3 \\
\hline Normal cellularity, mild clusters, superficial fibrillations & 2 \\
\hline Mild or moderate changes in cellularity, moderate fibrillations & 1 \\
\hline Severe changes in cellularity, severe fibrillations & 0 \\
\hline \multicolumn{2}{|l|}{ VIII: Chondrocyte clustering } \\
\hline No clusters & 2 \\
\hline$<25 \%$ of the cells & 1 \\
\hline $25-100 \%$ of the cells & 0 \\
\hline Total & Max. 23 \\
\hline
\end{tabular}

with SPSS 13.0 statistical software (SPSS, Inc., Chicago, IL); $p<0.05$ was considered statistically significant.

\section{RESULTS}

\section{dECM Expanded IPFSCs Exhibited Superior Capacity in Proliferation and Chondrogenic Differentiation}

To determine whether AECM expansion could rejuvenate IPFSCs' proliferation and chondrogenic differentiation, IPFSCs were grown on $\mathrm{AECM}$ and TCP for one passage followed by chondrogenic induction in a pellet culture system. We found that IPFSCs grown on AECM exhibited a glistening profile and
TABLE 2 | Adaptive reactions in cartilage resurfacing.

\begin{tabular}{lcccc}
\hline \multirow{2}{*}{ Group } & \multicolumn{4}{c}{ Category } \\
\cline { 2 - 5 } Bone cyst & \multicolumn{2}{c}{ Mononuclear cells } \\
\cline { 2 - 5 } $\mathbf{6}$ weeks & No. & Ratio & No. & Ratio \\
\hline PLGA & $3 \mathrm{~L}$ & $1 / 6$ & - & - \\
dECM & $10 \mathrm{R}$ & $1 / 8$ & $7 \mathrm{~L} / 7 \mathrm{R} / 8 \mathrm{~L} / 8 \mathrm{R}$ & $4 / 8$ \\
TCP & $17 \mathrm{R}$ & $1 / 8$ & $15 \mathrm{~L} / 15 \mathrm{R} / 18 \mathrm{~L} / 18 \mathrm{R}$ & $4 / 8$ \\
EMPTY & $26 \mathrm{R}$ & $1 / 6$ & - & - \\
$\mathbf{1 5}$ weeks & & & & $1 / 6$ \\
PLGA & $4 \mathrm{~L} / 5 \mathrm{R}$ & $2 / 6$ & $4 \mathrm{~L}$ & $1 / 8$ \\
dECM & $28 \mathrm{~L} / 28 \mathrm{R}$ & $2 / 8$ & $12 \mathrm{~L}$ & - \\
TCP & $20 \mathrm{R} / 21 \mathrm{~L} / 21 \mathrm{R} / 22 \mathrm{~L} / 22 \mathrm{R}$ & $5 / 8$ & - & - \\
EMPTY & $28 \mathrm{~L} / 28 \mathrm{R}$ & $2 / 6$ & - & \\
\hline
\end{tabular}

were arranged in the direction of matrix fibers below; in contrast, IPFSCs grown on TCP were larger in size and arranged in a disorderly fashion (Figure 2A). EdU incorporation data showed that dECM expanded IPFSCs had a $4.3 \%$ increase in percentage and $36.3 \%$ increase in median compared to TCP expanded cells (Figure 2B). After chondrogenic induction, we found that dECM expanded IPFSCs exhibited significantly higher expression levels of chondrogenic marker genes (Figure 2C), including SOX9, $A C A N$, and COL2A1, than the corresponding TCP group in a time-dependent manner for up to 14 days despite a drop in the expression of these genes at 30 days.

\section{Transduction of Lentivirus Showed a Limited Influence on IPFSCs' Stem Cell Properties}

To determine whether lentivirus transduction affected IPFSCs' proliferation and chondrogenic induction, IPFSCs were transduced with lentivirus carrying GFP followed by screening with puromycin to remove non-transduced cells (Figure 2D). PDT data showed comparable proliferation capacity in the IPFSCs with or without lentivirus transduction at passages 1, 4, and 5 following TCP expansion and at passage 5 following dECM expansion (Figure 2E). RT-qPCR data showed that, during chondrogenic induction, IPFSCs with or without lentivirus transduction had a comparable expression level of SOX9 despite an increase of $A C A N$ and a decrease of COL2A1 in those with lentivirus transduction (Figure 2F).

\section{dECM Expanded IPFSCs Developed Better Premature Cartilage Tissue Constructs Than TCP Expanded Cells}

Both dECM and TCP expanded IPFSCs (2.2 million each) were dynamically seeded into PLGA mesh scaffold $(5 \mathrm{~mm}$ diameter $\times 2 \mathrm{~mm}$ thickness) in a spinner flask system. A representative tissue construct is shown in Figure 2G. Three weeks after chondrogenic induction, under microscopy, the tissue constructs seeded with dECM expanded cells appeared thicker, with cells settled on the fibers of PLGA mesh, whereas those grown with TCP expanded cells were thinner, indicating 
TABLE 3 | Six-week and 15-week cartilage resurfacing graded by MODS.

\begin{tabular}{|c|c|c|c|c|c|c|c|c|c|}
\hline \multirow[t]{2}{*}{ Group } & \multicolumn{8}{|c|}{ Category } & \multirow[t]{2}{*}{ Total score } \\
\hline & $\mathbf{I}$ & II & III & IV & $\mathbf{v}$ & VI & VII & VIII & \\
\hline \multicolumn{10}{|c|}{6 weeks } \\
\hline PLGA & 3.33 & 0.50 & 0.17 & 1.17 & 1.67 & 0.50 & 2.33 & 1.00 & $10.67 \pm 5.82$ \\
\hline dECM & 2.00 & 0.50 & - & - & 1.50 & 0.63 & 2.25 & 0.88 & $7.75 \pm 3.49$ \\
\hline $\mathrm{TCP}$ & 2.25 & 0.50 & 0.13 & 0.50 & 1.63 & 0.75 & 2.00 & 1.00 & $8.75 \pm 4.83$ \\
\hline EMPTY & 7.67 & 2.00 & 1.00 & 1.00 & 1.83 & 2.00 & 2.00 & 1.00 & $18.50 \pm 0.84$ \\
\hline \multicolumn{10}{|c|}{15 weeks } \\
\hline PLGA & 5.33 & 1.00 & 0.83 & 1.83 & 1.50 & 1.83 & 1.67 & 1.00 & $15.00 \pm 3.35$ \\
\hline $\mathrm{dECM}$ & 3.75 & 1.38 & 0.50 & 1.13 & 2.00 & 1.25 & 2.00 & 1.00 & $13.00 \pm 5.61$ \\
\hline TCP & 5.50 & 1.25 & 0.63 & 1.13 & 1.75 & 1.13 & 2.00 & 1.00 & $14.38 \pm 3.81$ \\
\hline EMPTY & 7.67 & 1.83 & 1.17 & 1.67 & 1.83 & 1.33 & 2.00 & 1.00 & $18.50 \pm 1.38$ \\
\hline
\end{tabular}

greater cell density in the AECM group than the TCP group (Figure 2H). Histology data showed that, following three-week chondrogenic induction, AECM expanded IPFSCs yielded tissue constructs with a larger size and higher intensity of sulfated GAGs as stained by Alcian blue (Ab) and type II collagen (Col 2) immunostained by monoclonal antibody (Figure 2I). These observations were further supported by RT-qPCR, as tissue constructs made by $\mathrm{dECM}$ expanded cells had higher expression levels of chondrogenic marker genes SOX9, COL $2 A 1$, and $A C A N$ than the TCP group; interestingly, the $\mathrm{AECM}$ group had less expression of the hypertrophic marker gene COL10A1 (Figure 2J).

\section{Early Stage Evidence of Cartilage Resurfacing Using Different Approaches}

Premature tissue constructs from the dECM and TCP groups were used to fill in the defects with implantation of PLGA scaffold alone and the defect left untreated as controls. Six weeks after implantation, defects left untreated (the Empty group) exhibited the best cartilage regeneration with glistening, smooth, and whitish neotissue in most joint samples; however, in other groups, some defects remained uncovered or were partially covered with neotissue, showing a donor-dependent manner of cartilage regeneration. The best and worst examples of healed defects on both sides of the dECM group were exhibited by rabbit No. 10 and No. 7, respectively (Figure 3). Greatest healing of defects in the TCP group was found in rabbit Nos. 16 and 17, whereas healing was more limited in rabbit Nos. 15 and 18 (Figure 3). Despite lack of inflammatory signs in synovial tissue in all six-week groups, we found subchondral bone cysts in all groups and mononuclear cells in some groups (Table 2) as well as subchondral bone spurs in some rabbit joints, including rabbits Nos. 2 and 3 (left side) in the PLGA group and rabbit No. 9 in the dECM group (both left and right sides; Figure 3).

The above-mentioned morphological appearance of six-week cartilage resurfacing was further confirmed by histology and immunostaining (Figure 4). Most defects in the Empty group were filled with regenerated tissue having integrated at both sides and intensive staining of Alcian blue for sulfated GAGs and immunostaining for type II collagen as well as less staining of type I collagen located primarily on the surface of the neotissue, indicative of a mature articular cartilage (for example, in rabbit No. 25 on the left side). Bone spurs that were composed of regenerated tissue stained positively for sulfated GAGs and type II collagen, indicating the presence of hyaline cartilage, covered with a tissue stained positively for types I and II collagen, indicative of fibrocartilage (Figure 5). However, we also found subchondral bone cysts in some joints (No. 26, right side), which likely formed via an extension of regenerated cartilage; the wall of cysts expressed both types I and II collagen but not sulfated GAGs, suggestive of fibrocartilage. The other groups included the "best" healing of osteochondral defects such as rabbit No. 2 (right side) in the PLGA group, No. 10 (right side) in the dECM group, and No. 17 (right side) in the TCP group. The "worst" healing of osteochondral defects was found in rabbit No. 1 (left side) in the PLGA group, No. 7 (left side) in the dECM group, and No. 15 (left side) in the TCP group. The MODS scores ("Empty" versus "PLGA", $p=0.009$; "Empty" versus "dECM", $p=0.000$; and "Empty" versus "TCP", $p=0.000$ ) (Table 3) support the above observation, indicating that the Empty group outperformed the other implantation groups in cartilage resurfacing.

\section{Late Stage Evidence of Cartilage Resurfacing Using Different Approaches}

The Empty group exhibited superior cartilage healing as compared to all other groups (Figure 6), which was supported by their MODS scores ("Empty" vs. "PLGA", $p=0.039$; "Empty" vs. "dECM", $p=0.038$; and "Empty" vs. "TCP", $p=0.028$ ) (Table 3). Compared to those of six-week rabbit joints, cartilage regeneration in the 15-week joints of the Empty group did not have a significant change; however, other groups at 15 weeks had greatly improved in osteochondral defect repairs, particularly for the dECM and TCP groups which had implantation of tissue constructs (Figures 6, 7).

There were no signs of inflammation or bone spurs in 15-week joints in any group. Compared to six-week cartilage resurfacing, we found more bone cysts in each group and mononuclear cells surrounding regenerated tissue in some groups (Table 2), particularly in rabbit No. 4 (left side) in the PLGA group (Figure 7). The MODS score of cartilage resurfacing with tissue 
constructs (DECM and TCP groups) exhibited a significant increase at 15 weeks compared to that at six weeks ( $p=0.041$ and $p=0.022$, respectively) (Table 3 ).

\section{Tracking of Implanted Cells Labeled With GFP}

Under immunofluorescence microscopy, GFP expression in both in vitro tissue constructs was maintained from expanded IPFSCs after lentivirus transduction and puromycin screening (Figure 8A). However, GFP expression in the regenerated cartilage tissue was undetectable in all groups at both sixweek (Figure 8B) and 15-week time points (Figure 8C), indicating that implanted IPFSCs might not be directly involved in cartilage resurfacing. In order to exclude the influence of decalcification on the immunofluorescence signal, an immunohistochemical staining was conducted using a monoclonal antibody against GFP. The result confirmed immunofluorescence data (Figures 8A-C) - positive staining in in vitro tissue construct samples (Figure 8D) but not in in vivo resurfacing cartilage from the tissue construct groups (Figure 8E).

\section{DISCUSSION}

The goal of this study was to assess the feasibility of using a dECM-mediated-tissue engineering approach to treat osteochondral defects in young rabbits. Interestingly, we found that the Empty group (with defects left untreated) exhibited superior cartilage resurfacing at both six weeks and 15 weeks compared to the PLGA, TCP, and AECM groups. In addition, the MODS score of 15-week cartilage resurfacing in the Empty group had no significant change compared to that of six-week samples, indicating that 7.7-month-old rabbits still had a strong capacity to self-heal cartilage defects up to six weeks until 9 months of age (7.7 months +6 weeks) by which time the rabbits had lost this ability. Consistent with a previous report, (He et al., 2009) despite the excellent chondrogenic capacity and less hypertrophy of dECM expanded IPFSCs evaluated in vitro, tissue constructs developed by dECM expanded cells failed to show an advantage for cartilage resurfacing over those from TCP expanded cells. However, the MODS scoring data indicated that cartilage resurfacing was significantly improved in both tissue construct groups at 15 weeks compared to those at six weeks, suggesting that a tissue-engineering approach plays a unique role in cartilage resurfacing of adult rabbits despite the fact that selfhealing dominates cartilage repair in young rabbits less than 9 months old. Although the implanted cells were pre-labeled with GFP, no positive staining was detectable in the resurfaced cartilage from both six-week and 15-week osteochondral defects, suggesting that the implanted cells might not be directly involved in cartilage resurfacing.

As a conventionally used animal model, the rabbit has a strong ability for spontaneous cartilage repair, (Chu et al., 2010; Anderson et al., 2014) which implies the chondrocytes' capacity in proliferation and deposition of functional matrix in the absence of vascular elements (Dell'Accio and Vincent, 2010).
Therefore, it is important to choose rabbits with minimized self-healing capacity for a cartilage regeneration study. NZW rabbits' skeletal maturity is reported to occur between four and six months, (Reinholz et al., 2004; Hunziker et al., 2007) but some groups believe rabbits become skeletally mature between six and nine months of age (Rudert, 2002; Isaksson et al., 2010) or between seven and eight months of age, (Masoud et al., 1986) with an age of eight months and above, (Wei et al., 1997; Wei and Messner, 1999; Pei et al., 2009) or with an age of nine months or more (Hoemann et al., 2007). The finding in this study indicates there is no further growth of cartilage when rabbits reach nine months old, the age when a young rabbit becomes an adult (Laber-Laird et al., 1996), which might be attributed to cartilage maturation, meeting the guidelines recommended by the International Cartilage Regeneration \& Joint Preservation Society (ICRS), as opposed to skeletal maturity (Hurtig et al., 2011). Cartilage maturation is defined by an intact tidemark that is the calcified cartilage layer and complete subchondral bone plate with minimized vascularization (Müller-Gerbl, 1998; Madry et al., 2010). Given a 3-mm diameter cartilage lesion defined as the critical sized defect in a rabbit knee model, in this study, $4.76 \mathrm{~mm}$ diameter $\times 2 \mathrm{~mm}$ depth osteochondral defects that did not penetrate subchondral bone in the Empty group were filled with a neotissue with intensive expression of sulfated GAGs and type II collagen but less expression of type I collagen, indicative of a hyaline articular cartilage. These findings are in contrast to fibrocartilage with inferior mechanical properties as reported in the Empty group by Barron et al. Barron and coworkers reported that type I collagen was evident throughout the neotissue along with type II collagen, (Barron et al., 2015) likely contributed by bone marrow stomal cells released from penetrating subchondral bone through a 3-mm-depth cartilage defect model (Wei and Messner, 1999).

Some researchers think articular cartilage is immunoprivileged because of cartilage's avascular and dense ECM; however, this view has been questioned by antigenic evidence of chondrocytes and associated ECM, (Revell and Athanasiou, 2009; Arzi et al., 2015). As shown by the cartilage resurfacing joint samples in the PLGA group, implant materials evoked a robust and constant inflammatory response evidenced by the presence of a large number of mononuclear cells surrounding subchondral bone at 15 weeks postoperatively. However, there was no sign of immune rejection observed during tissue harvesting. This finding confirmed the view that the recipient could reject a xenogeneic but not allogeneic implant (Pei et al., 2009, 2010; Arzi et al., 2015). Increasing evidence shows that the discrepancy exists in response to foreign implants between young and old recipients due to the changed local matrix microenvironment (Lynch and Pei, 2014; Brown et al., 2017). For example, Hachim et al. (2017) reported that, compared to eight-week-old mice, 18-month-old mice exhibited significant differences in macrophage polarization during the early phase of implantation and delayed resolution of the host response. Colvin et al. (2017) demonstrated that older transplant recipients exhibited reduced frequency of acute allograft rejection due to immunosenescence. The above-mentioned evidence might partially explain why implant groups were not better in cartilage 
resurfacing than the Empty group (left untreated), at least in the earlier time points assessed in this study, such as six weeks and 15 weeks.

Abnormal reactions during cartilage resurfacing include, but are not limited to, osteophytes, bone cysts, and synovial tissue inflammation (Hoemann et al., 2011). In this study, we did not observe synovial tissue inflammation, but both osteophytes and bone cysts existed in some groups at some time points. In animal models, subchondral bone cysts can appear following the treatment of cartilage repair, (Benazzo et al., 2008; Getgood et al., 2012) suggesting abnormal biological remodeling (Henderson et al., 2003) resulting from unusual mechanobiology (Von Rechenberg et al., 2003; Pallante-Kichura et al., 2013). Different from previous findings that bone cysts were only observed in the Empty group but not in the cellfree or cell-seeded scaffold groups (Barron et al., 2015) and that bone cysts occurred in the implantation with either collagenGAG or PLGA scaffold, (Getgood et al., 2012) we found that subchondral bone cysts existed in all groups at both time points; however, cartilage resurfacing at 15 weeks postoperatively had more bone cysts than the earlier time point at six weeks. Since both time points designed for observation were still in the early phase of cartilage resurfacing, the wall of bone cysts was characterized as fibrocartilage, which positively stained for both types I and II collagen but was negative for sulfated GAG. This finding is in contrast to previous reports in which mature bone cysts were surrounded by bone tissue (Chen et al., 2011; Pallante-Kichura et al., 2013).

Potential mechanisms underlying the role of mesenchymal stromal/stem cells in cartilage repair include two viewpoints, via direct (chondrogenic differentiation) and/or indirect (secretion of paracrine factors) strategies (Meirelles Lda et al., 2009; Toh et al., 2014). Previous studies indicated that only a small fraction of labeled cells traceable in the repair tissue originated from the implanted cells (Grande et al., 1989; Dell'Accio et al., 2003; Tatebe et al., 2005; Blanke et al., 2009). In this study, we were unable to trace at either six-weeks or 15-weeks postoperatively using both immunofluorescence microscopy and immunohistochemical staining for GFP signal, indicating that trophic factors released by the implanted cells might contribute to cartilage resurfacing rather than direct differentiation. In comparison to defects at six and 15 weeks, both tissue construct groups exhibited a significant improvement in cartilage resurfacing indicting that the impact of implanted cells on reparative cells might dominate osteochondral defect repair and play a more critical role than the implanted cells themselves (Muschler et al., 2010).

Taken together, in this study, young NZW rabbits (around 7.7 months old) exhibited a strong ability for simultaneous cartilage regeneration until nine months of age. Compared to TCP expanded IPFSCs, dECM expanded cells presented a

\section{REFERENCES}

Anderson, J. A., Little, D., Toth, A. P., Moorman, C. T. III, Tucker, B. S., Ciccotti, M. G., et al. (2014). Stem cell therapies for knee cartilage repair: the current robust chondrogenic capacity under in vitro induction in both pellet and tissue construct cultures, but this advantage was not reflected in cartilage resurfacing of osteochondral defects in young rabbits. Interestingly, both tissue construct groups displayed improved cartilage resurfacing in a time-dependent manner, indicating that a tissue-engineering cartilage graft can facilitate osteochondral defect repair in adult rabbits, in which the untreated group did not have improvement. In the future, the dECM-based tissue-engineering approach will be further explored to treat osteochondral defects in models utilizing older animals, including adult and elderly rabbits with mature cartilage.

\section{DATA AVAILABILITY STATEMENT}

The raw data supporting the conclusions of this article will be made available by the authors, without undue reservation.

\section{ETHICS STATEMENT}

The animal study was reviewed and approved by WVU IACUC committee.

\section{AUTHOR CONTRIBUTIONS}

ZL performed collection and assembly of data, data analysis and interpretation, manuscript writing, and final approval. SZ, JV, AS, and JP performed collection of data and final approval of manuscript. GG performed data analysis and interpretation and final approval of manuscript. LY performed data analysis and interpretation, final approval of manuscript, and financial support. MP performed conception and design, data analysis and interpretation, manuscript writing and final approval, and financial support. All authors contributed to the article and approved the submitted version.

\section{ACKNOWLEDGMENTS}

We thank Suzanne Danley for editing the manuscript. This work was supported by Research Grants from the Musculoskeletal Transplant Foundation (MTF) and the National Institutes of Health (1R01AR067747-01A1). We also would like to acknowledge the WVU Flow Cytometry and Microscope Imaging Facility and the grants that support these facility, TME CoBRE grant P20GM121322, and WV-INBRE grant P20 GM103434 and P30GM103488.

status of preclinical and clinical studies. Am. J. Sports Med. 42, 2253-2261. doi: 10.1177/0363546513508744

Arzi, B., DuRaine, G. D., Lee, C. A., Huey, D. J., Borjesson, D. L., Murphy, B. G., et al. (2015). Cartilage immunoprivilege depends on donor source 
and lesion location. Acta Biomater. 23, 72-81. doi: 10.1016/j.actbio.2015. 05.025

Barron, V., Merghani, K., Shaw, G., Coleman, C. M., Hayes, J. S., Ansboro, S., et al. (2015). Evaluation of cartilage repair by mesenchymal stem cells seeded on a PEOT/PBT scaffold in an osteochondral defect. Ann. Biomed. Eng. 43, 2069-2082. doi: 10.1007/s10439-015-1246-2

Benazzo, F., Cadossi, M., Cavani, F., Fini, M., Giavaresi, G., Setti, S., et al. (2008). Cartilage repair with osteochondral autografts in sheep: effect of biophysical stimulation with pulsed electromagnetic fields. J. Orthop. Res. 26, 631-642. doi: 10.1002/jor.20530

Blanke, M., Carl, H. D., Klinger, P., Swoboda, B., Hennig, F., and Gelse, K. (2009). Transplanted chondrocytes inhibit endochondral ossification within cartilage repair tissue. Calcif Tissue Int. 85, 421-433. doi: 10.1007/s00223-0 09-9288-9

Brown, B. N., Haschak, M. J., Lopresti, S. T., and Stahl, E. C. (2017). Effects of age-related shifts in cellular function and local microenvironment upon the innate immune response to implants. Semin. Immunol. 29, 24-32. doi: 10.1016/ j.smim.2017.05.001

Chen, H., Chevrier, A., Hoemann, C. D., Sun, J., Ouyang, W., and Buschmann, M. D. (2011). Characterization of subchondral bone repair for marrowstimulated chondral defects and its relationship to articular cartilage resurfacing. Am. J. Sports Med. 39, 1731-1740. doi: 10.1177/0363546511403282

Chu, C. R., Szczodry, M., and Bruno, S. (2010). Animal models for cartilage regeneration and repair. Tissue Eng. Part B Rev. 16, 105-115. doi: 10.1089/ten. teb. 2009.0452

Colvin, M. M., Smith, C. A., Tullius, S. G., and Goldstein, D. R. (2017). Aging and the immune response to organ transplantation. J. Clin. Invest. 127, 2523-2529. doi: $10.1172 /$ jci90601

Dell'Accio, F., Vanlauwe, J., Bellemans, J., Neys, J., De Bari, C., and Luyten, F. P. (2003). Expanded phenotypically stable chondrocytes persist in the repair tissue and contribute to cartilage matrix formation and structural integration in a goat model of autologous chondrocyte implantation. J. Orthop Res. 21, 123-131. doi: 10.1016/s0736-0266(02)00090-6

Dell'Accio, F., and Vincent, T. L. (2010). Joint surface defects: clinical course and cellular response in spontaneous and experimental lesions. Eur. Cell Mater. 20, 210-217. doi: 10.22203/ecm.v020a17

Galeano-Garces, C., Camilleri, E. T., Riester, S. M., Dudakovic, A., Larson, D. R., $\mathrm{Qu}, \mathrm{W}$., et al. (2017). Molecular validation of chondrogenic differentiation and hypoxia responsiveness of platelet-Lysate expanded adipose tissue-derived human mesenchymal stromal cells. Cartilage 8, 283-299. doi: 10.1177/ 1947603516659344

Getgood, A. M., Kew, S. J., Brooks, R., Aberman, H., Simon, T., Lynn, A. K., et al. (2012). Evaluation of early-stage osteochondral defect repair using a biphasic scaffold based on a collagen glycosaminoglycan biopolymer in a caprine model. Knee 19, 422-430. doi: 10.1016/j.knee.2011.03.011

Gilsanz, V., Roe, T. F., Gibbens, D. T., Schulz, E. E., Carlson, M. E., Gonzalez, O., et al. (1988). Effect of sex steroids on peak bone density of growing rabbits. Am. J. Physiol. 255, E416-E421.

Grande, D. A., Pitman, M. I., Peterson, L., Menche, D., and Klein, M. (1989). The repair of experimentally produced defects in rabbit articular cartilage by autologous chondrocyte transplantation. J. Orthop Res. 7, 208-218. doi: 10. 1002/jor.1100070208

Hachim, D., Wang, N., Lopresti, S. T., Stahl, E. C., Umeda, Y. U., Rege, R. D., et al. (2017). Effects of aging upon the host response to implants. J. Biomed. Mater. Res. A 105, 1281-1292. doi: 10.1002/jbm.a.36013

Han, S. H., Kim, Y. H., Park, M. S., Kim, I. A., Shin, J. W., Yang, W. I., et al. (2008). Histological and biomechanical properties of regenerated articular cartilage using chondrogenic bone marrow stromal cells with a PLGA scaffold in vivo. J. Biomed. Mat. Res. Part A. 87A, 850-861. doi: 10.1002/jbm.a.31828

He, F., Chen, X., and Pei, M. (2009). Reconstruction of an in vitro tissue-specific microenvironment to rejuvenate synovium-derived stem cells for cartilage tissue engineering. Tissue Eng. Part A. 15, 3809-3821. doi: 10.1089/ten.tea.2009. 0188

He, F., and Pei, M. (2013). Extracellular matrix enhances differentiation of adipose stem cells from infrapatellar fat pad toward chondrogenesis. J. Tissue Eng. Regen. Med. 7, 73-84. doi: 10.1002/term.505

Henderson, I. J., Tuy, B., Connell, D., Oakes, B., and Hettwer, W. H. (2003). Prospective clinical study of autologous chondrocyte implantation and correlation with MRI at three and 12 months. J. Bone Joint Surg. Br. 85B, 1060-1066. doi: 10.1302/0301-620x.85b7.13782

Hoemann, C., Kandel, R., Roberts, S., Saris, D. B., Creemers, L., MainilVarlet, P., et al. (2011). International Cartilage Repair Society (ICRS) recommended guidelines for histological endpoints for cartilage repair studies in animal models and clinical trials. Cartilage 2, 153-172. doi: 10.1177/ 1947603510397535

Hoemann, C. D., Sun, J., McKee, M. D., Chevrier, A., Rossomacha, E., Rivard, G. E., et al. (2007). Chitosan-glycerol phosphate/blood implants elicit hyaline cartilage repair integrated with porous subchondral bone in microdrilled rabbit defects. Osteoarthritis Cartilage 15, 78-89. doi: 10.1016/j.joca.2006.06.015

Hunziker, E. B., Kapfinger, E., and Geiss, J. (2007). The structural architecture of adult mammalian articular cartilage evolves by a synchronized process of tissue resorption and neoformation during postnatal development. Osteoarthritis Cartilage 15, 403-413. doi: 10.1016/j.joca.2006.09.010

Hurtig, M. B., Buschmann, M. D., Fortier, L. A., Hoemann, C. D., Hunziker, E. B., Jurvelin, J. S., et al. (2011). Preclinical studies for cartilage repair: recommendations from the International Cartilage Repair Society. Cartilage 2, 137-152. doi: 10.1177/1947603511401905

Isaksson, H., Harjula, T., Koistinen, A., Iivarinen, J., Seppänen, K., Arokoski, J. P., et al. (2010). Collagen and mineral deposition in rabbit cortical bone during maturation and growth: effects on tissue properties. J. Orthop Res. 28, 1626-1633. doi: $10.1002 /$ jor. 21186

Laber-Laird, K., Flecknell, P., and Swindle, M. (1996). Handbook of Rodent and Rabbit Medicine. Oxford: Butterworth-heinemann.

Li, J., and Pei, M. (2010). Optimization of an in vitro three-dimensional microenvironment to reprogram synovium-derived stem cells for cartilage tissue engineering. Tissue Eng. Part A 17, 703-712. doi: 10.1089/ten.tea.2010. 0339

Li, J., and Pei, M. A. (2018). Protocol to prepare decellularized stem cell matrix for rejuvenation of cell expansion and cartilage regeneration. Methods Mol. Biol. 1577, 147-154. doi: 10.1007/7651_2017_27

Li, J. T., He, F., and Pei, M. (2011). Creation of an in vitro microenvironment to enhance human fetal synovium-derived stem cell chondrogenesis. Cell Tissue Res. 345, 357-365. doi: 10.1007/s00441-011-1212-8

Li, J. T., and Pei, M. (2012). Cell senescence: a challenge in cartilage engineering and regeneration. Tissue Eng. Part B 18, 270-287. doi: 10.1089/ten.teb.2011.0583

Lynch, K., and Pei, M. (2014). Age associated communication between cells and matrix: a potential impact on stem cell-based tissue regeneration strategies. Organogenesis 10, 289-298. doi: 10.4161/15476278.2014.970089

Madry, H., van Dijk, C. N., and Mueller-Gerbl, M. (2010). The basic science of the subchondral bone. Knee Surg. Sports Traumatol. Arthrosc. 18, 419-433. doi: 10.1007/s00167-010-1054-z

Masoud, I., Shapiro, F., and Moses, A. (1986). Tibial epiphyseal development: a cross-sectional histologic and histomorphometric study in the New Zealand white rabbit. J. Orthop Res. 4, 212-220. doi: 10.1002/jor.1100040210

Meirelles Lda, S., Fontes, A. M., Covas, D. T., and Caplan, A. I. (2009). Mechanisms involved in the therapeutic properties of mesenchymal stem cells. Cytokine Growth Factor Rev. 20, 419-427. doi: 10.1016/j.cytogfr.2009.10.002

Müller-Gerbl, M. (1998). The subchondral bone plate. Adv. Anat. Embryol. Cell Biol. 141, 1-134. doi: 10.1007/978-3-642-72019-2_1

Muschler, G. F., Raut, V. P., Patterson, T. E., Wenke, J. C., and Hollinger, J. O. (2010). The design and use of animal models for translational research in bone tissue engineering and regenerative medicine. Tissue Eng. Part B Rev. 16, 123-145. doi: 10.1089/ten.teb.2009.0658

Newman, E., Turner, A. S., and Wark, J. D. (1995). The potential of sheep for the study of osteopenia: current status and comparison with other animal models. Bone 16, 277-284.

Nukavarapu, S. P., and Dorcemus, D. L. (2013). Osteochondral tissue engineering: Current strategies and challenges. Biotechnol. Adv. 31, 706-721. doi: 10.1016/j. biotechadv.2012.11.004

O'Driscoll, S. W., Keeley, F. W., and Salter, R. B. (1986). The chondrogenic potential of free autogenous periosteal grafts for biological resurfacing of major full-thickness defects in joint surfaces under the influence of continuous passive motion. An experimental investigation in the rabbit. J. Bone Joint Surg. Am. 68, 1017-1035. doi: 10.2106/00004623-198668070-00008

Pallante-Kichura, A. L., Cory, E., Bugbee, W. D., and Sah, R. L. (2013). Bone cysts after osteochondral allograft repair of cartilage defects in goats suggest 
abnormal interaction between subchondral bone and overlying synovial joint tissues. Bone 57, 259-268. doi: 10.1016/j.bone.2013.08.011

Pei, M. (2017). Environmental preconditioning rejuvenates stem cells chondrogenic potential. Biomaterials 117, 10-23. doi: 10.1016/j.biomaterials. 2016.11.049

Pei, M., He, F., Boyce, B. M., and Kish, V. L. (2009). Repair of full-thickness femoral condyle cartilage defects using allogeneic synovial cell-engineered tissue constructs. Osteoarthritis Cartilage 17, 714-722. doi: 10.1016/j.joca.2008. 11.017

Pei, M., He, F., Li, J., Tidwell, J. E., Jones, A. C., and McDonough, E. B. (2013). Repair of large animal partial-thickness cartilage defects through intraarticular injection of matrix-rejuvenated synovium-derived stem cells. Tissue Eng. Part A 19, 1144-1154. doi: 10.1089/ten.tea.2012.0351

Pei, M., He, F., and Wei, L. (2011). Three-dimensional cell expansion substrate for cartilage tissue engineering and regeneration: a comparison in decellularized matrix deposited by synovium-derived stem cells and chondrocytes. J. Tissue Sci Eng 2:2.

Pei, M., Seidel, J., Vunjak-Novakovic, G., and Freed, L. E. (2002a). Growth factors for sequential cellular de- and redifferentiation in tissue engineering. Biochem. Biophys. Res. Commun. 294, 149-154. doi: 10.1016/s0006-291x(02)00439-4

Pei, M., Solchaga, L. A., Seidel, J., Zeng, L., Vunjak-Novakovic, G., Caplan, A. I., et al. (2002b). Bioreactors mediate the effectiveness of tissue engineering scaffolds. FASEB J. 16, 1691-1694. doi: 10.1096/fj.02-0083fje

Pei, M., Yan, Z., Shoukry, M., and Boyce, B. M. (2010). Failure of xenoimplantation using porcine synovium-derived stem cell-based cartilage tissue constructs for the repair of rabbit osteochondral defects. J. Orthop. Res. 28, 1064-1070. doi: 10.1002/jor.21096

Pizzute, T., Zhang, Y., He, F., and Pei, M. (2016). Ascorbate-dependent impact on cell-derived matrix in modulation of stiffness and rejuvenation of infrapatellar fat derived stem cells toward chondrogenesis. Biomed. Mater. 11:045009. doi: 10.1088/1748-6041/11/4/045009

Reinholz, G. G., Lu, L., Saris, D. B., Yaszemski, M. J., and O’Driscoll, S. W. (2004). Animal models for cartilage reconstruction. Biomaterials 25, 1511-1521. doi: 10.1016/s0142-9612(03)00498-8

Revell, C. M., and Athanasiou, K. A. (2009). Success rates and immunologic responses of autogenic, allogenic, and xenogenic treatments to repair articular cartilage defects. Tissue Eng. Part B Rev 15, 1-15. doi: 10.1089/ten.teb.2008.0189

Rudert, M. (2002). Histological evaluation of osteochondral defects: consideration of animal models with emphasis on the rabbit, experimental setup, followup and applied methods. Cells Tissues Organs 171, 229-240. doi: 10.1159/ 000063125

Rutgers, M., van Pelt, M. J., Dhert, W. J., Creemers, L. B., and Saris, D. B. (2010). Evaluation of histological scoring systems for tissue-engineered, repaired and osteoarthritic cartilage. Osteoarthritis Cartilage 18, 12-23. doi: 10.1016/j.joca. 2009.08.009

Smith, G. D., Knutsen, G., and Richardson, J. B. (2005). A clinical review of cartilage repair techniques. J. Bone Joint Surg. Br. 87, 445-449.

Sun, Y., Chen, S., and Pei, M. (2018). Comparative advantages of infrapatellar fat pad: an emerging stem cell source for regenerative medicine. Rheumatology 57, 2072-2086. doi: 10.1093/rheumatology/ kex487

Tatebe, M., Nakamura, R., Kagami, H., Okada, K., and Ueda, M. (2005). Differentiation of transplanted mesenchymal stem cells in a large osteochondral defect in rabbit. Cytotherapy 7, 520-530. doi: 10.1080/1465324050 0361350

Toh, W. S., Foldager, C. B., Pei, M., and Hui, J. H. (2014). Advances in mesenchymal stem cell-based strategies for cartilage repair and regeneration. Stem. Cell Rev. Rep. 10, 686-696. doi: 10.1007/s12015-014-9526-Z

Uematsu, K., Hattori, K., Ishimoto, Y., Yamauchi, J., Habata, T., Takakura, Y., et al. (2005). Cartilage regeneration using mesenchymal stem cells and a three-dimensional poly-lactic-glycolic acid (PLGA) scaffold. Biomaterials. 26, 4273-4279. doi: 10.1016/j.biomaterials.2004.10.037

Von Rechenberg, B., Akens, M. K., Nadler, D., Bittmann, P., Zlinszky, K., Kutter, A., et al. (2003). Changes in subchondral bone in cartilage resurfacingan experimental study in sheep using different types of osteochondral grafts. Osteoarthritis Cartilage 11, 265-277. doi: 10.1016/s1063-4584(03) 00006-2

Wang, T., Hill, R. C., Dzieciatkowska, M., Zhu, L., Infante, A. M., Hu, G., et al. (2020). Site-dependent lineage preference of adipose stem cells. Front. Cell Dev. Biol. 8:237.

Wang, Y. M., Fu, Y. W., Yan, Z. Q., Zhang, X. B., and Pei, M. (2019). Impact of fibronectin knockout on proliferation and differentiation of human infrapatellar fat pad-derived stem cells. Front. Bioeng. Biotechnol. 7:321.

Wang, Y. M., Hu, G. Q., Hill, R. C., Dzieciatkowska, M., Hansen, K. C., Zhang, X. B., et al. (2020). Matrix reverses immortalization-mediated stem cell fate determination. Biomaterials 265:120387. doi: 10.1016/j.biomaterials.2020. 120387

Wei, X., Gao, J., and Messner, K. (1997). Maturation-dependent repair of untreated osteochondral defects in the rabbit knee joint. J. Biomed. Mater Res. 34, 63-72. doi: 10.1002/(sici)1097-4636(199701)34:1<63::aid-jbm9>3.0.co;2-1

Wei, X., and Messner, K. (1999). Maturation-dependent durability of spontaneous cartilage repair in rabbit knee joint. J. Biomed. Mater. Res. 46, 539-548. doi: 10.1002/(sici)1097-4636(19990915)46:4<539::aid-jbm12>3.0.co;2-s

Willers, C., Wood, D. J., and Zheng, M. H. (2003). A current review on the biology and treatment of articular cartilage defects (Part I \& Part II). J. Musculoskelet Res. 7, 157-181. doi: 10.1142/s0218957703001125

Conflict of Interest: The authors declare that the research was conducted in the absence of any commercial or financial relationships that could be construed as a potential conflict of interest.

Copyright (c) $2020 \mathrm{Lu}$, Zhou, Vaida, Gao, Stewart, Parenti, Yan and Pei. This is an open-access article distributed under the terms of the Creative Commons Attribution License (CC BY). The use, distribution or reproduction in other forums is permitted, provided the original author(s) and the copyright owner(s) are credited and that the original publication in this journal is cited, in accordance with accepted academic practice. No use, distribution or reproduction is permitted which does not comply with these terms. 